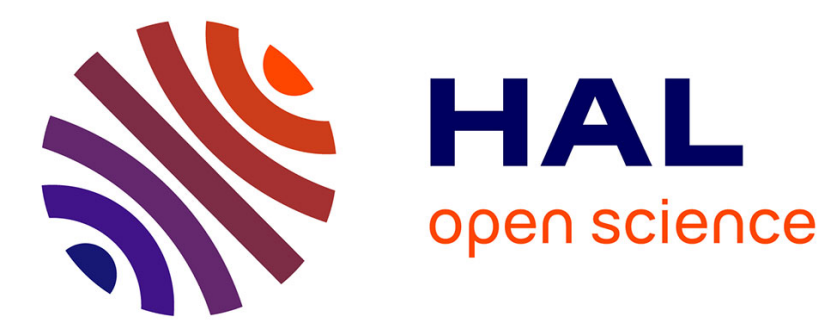

\title{
Electronic properties of mixed uranium-thorium monosulphides (U xTh1-x)S
}

J. Danan, C.H. de Novion, Y. Guerin, F.A. Wedgwood, M. Kuznietz

\section{To cite this version:}

J. Danan, C.H. de Novion, Y. Guerin, F.A. Wedgwood, M. Kuznietz. Electronic properties of mixed uranium-thorium monosulphides (U xTh1-x)S. Journal de Physique, 1976, 37 (10), pp.1169-1186. 10.1051/jphys:0197600370100116900 . jpa-00208514

\section{HAL Id: jpa-00208514 https://hal.science/jpa-00208514}

Submitted on 1 Jan 1976

HAL is a multi-disciplinary open access archive for the deposit and dissemination of scientific research documents, whether they are published or not. The documents may come from teaching and research institutions in France or abroad, or from public or private research centers.
L'archive ouverte pluridisciplinaire HAL, est destinée au dépôt et à la diffusion de documents scientifiques de niveau recherche, publiés ou non, émanant des établissements d'enseignement et de recherche français ou étrangers, des laboratoires publics ou privés. 


\author{
Classification \\ Physics Abstracts \\ $8.531-8.534-8.535$
}

\title{
ELECTRONIC PROPERTIES OF MIXED URANIUM-THORIUM MONOSULPHIDES $\left(\mathrm{U}_{x} \mathrm{Th}_{1-x}\right) \mathrm{S}$
}

\author{
J. DANAN, C. H. DE NOVION, Y. GUERIN \\ DECPu, C.E.N., B.P. 6, 92260 Fontenay-aux-Roses, France \\ F. A. WEDGWOOD \\ AERE, Harwell, Didcot, Oxfordshire, England \\ and M. KUZNIETZ \\ Soreq Nuclear Research Center, Yavne, Israel
}

\begin{abstract}
Résumé. - Nous avons mesuré l'aimantation, la diffusion magnétique des neutrons et la chaleur spécifique entre 1,5 et $300 \mathrm{~K}$ de monosulfures mixtes d'uranium et de thorium $\left(\mathrm{U}_{x} \mathrm{Th}_{1-x}\right) \mathrm{S}$ contenant une proportion importante d'uranium $(x \geqslant 0,20)$. L'ordre ferromagnétique à grande distance est observé à basse température pour $0,43<x \leqslant 1$, mais pour $x<0,43$, il n'y a pas d'ordre magnétique à grande distance. L'aimantation spontanée et la température de Curie décröissent linéairement avec la concentration en uranium. La chaleur spécifique électronique est maximale à la concentration critique $x_{\mathrm{c}}=0,43$. Nos mesures de chaleur spécifique n'ont pas montré d'anomalies de Schottky et nous n'avons pas observé de niveaux de champ cristallin en diffusion inélastique de neutrons. L'ensemble de nos résultats suggère une description de bande plutôt qu'une description localisée pour les électrons $5 f$ de l'uranium.
\end{abstract}

Abstract. - We have measured bulk magnetization, neutron magnetic scattering and specific heat between 1.5 and $300 \mathrm{~K}$ of mixed uranium-thorium monosulphides $\left(\mathrm{U}_{x} \mathrm{Th}_{1-x}\right) \mathrm{S}$ with large uranium concentrations $(x \geqslant 0.20)$. Long-range ferromagnetic order is observed at low temperature for $0.43<x \leqslant 1$, but no long-range magnetic order occurs for $x<0.43$. Magnetization and Curie temperature decrease linearly with uranium content. The electronic specific heat is maximum at the critical cońcentration $x_{\mathrm{c}}=0.43$. Our experiments failed to reveal Schottky anomalies in specific heat or crystal-field levels by inelastic neutron scattering. Our results favour a band description rather than a localised description for uranium 5 f electrons.

1. Introduction. - Uranium and thorium monosulphides (US and ThS) have at room temperature the $\mathrm{NaCl}$ crystalline structure [1] and a metallic electrical conductivity [2]. While ThS shows a small temperature independent paramagnetism [3], US is ferromagnetic below $178 \mathrm{~K}$ [4]. The precise study of the magnetic form factor of US by neutron diffraction techniques [5] has shown that the uranium magnetic moment is mostly due to the existence of unfilled $5 f$ orbitals; but the electronic structure of these orbitals is not yet well understood.

The magnetic properties of the metallic actinide compounds have usually been interpreted in terms of localized $5 f$ configuration. In particular, GrunzweigGenossar et al. [6] have explained the values of the magnetic moments and Curie temperatures and the nature of the magnetic order in the uranium pnictides and chalcogenides by attributing the $5 \mathrm{f}^{2}$ configuration to the uranium ion in all these compounds.
However, in the case of US, this localized description of the $5 \mathrm{f}$ shell is apparently in contradiction with the strong electronic specific heat [7], band calculations [8] and photo-emission measurements [9], all three of which suggest narrow $5 \mathrm{f}-6 \mathrm{~d}$ bands crossing the Fermi level.

To improve our understanding of the electronic structure of US, we have studied the solid solution $\left(\mathrm{U}_{x} \mathrm{Th}_{1-x}\right) \mathrm{S}$, the existence of which was known by the works of Shalek [10] and of Cater et al. [11].

The purposes of this study were :

(1) To test the model of Grunzweig-Genossar et al. [6] : effectively, by alloying uranium sulphide with thorium sulphide one should diminish the exchange field while keeping the crystalline field roughly constant.

(2) To test the band nature of the $5 f$ electrons in these alloys by measuring the electronic specific heat. 
(3) To look for crystal field levels by inelastic neutron scattering, and by numerical analysis of the specific heat.

Allbutt et al. [4] and Chechernikov et al. [13] have already examined the magnetic properties of this solid solution between 80 and $300 \mathrm{~K}$. Also, Tetenbaum [2] has measured some transport properties between 300 and $1300 \mathrm{~K}$. Fisk and Coles [12] explained his results by the filling-up of a $5 f$ band. We should note that the $\left(\mathrm{U}_{x} \mathrm{Th}_{1-x}\right) \mathrm{S}$ samples of Allbutt et al. [4] all showed a ferromagnetic transition at $178 \mathrm{~K}$; this was attributed to ferromagnetic clusters, and in consequence these authors did not analyse their results.

We report here on the specific heat measurements (already partly presented [14]), magnetization curves in the ferromagnetic state, and neutron scattering. This follows the measurements of electrical resistivity and magnetic susceptibility, previously published $[14,15]$.

2. Electronic properties of actinide monosulphides. - The valence states of the actinide monosulphides are mostly constructed with the $7 \mathrm{~s}, 6 \mathrm{~d}$, $5 \mathrm{f}$ wave functions of the metal atom and with the $3 p$ and perhaps $3 \mathrm{~s}$ wave functions of the sulphur atom. The overlap of these orbitals leads to the formation of several bands crossing the Fermi level.

2.1 BAND STRUCTURE. - The only actinide sulphide for which band calculations have been made is the uranium monosulphide US in its paramagnetic state $[8,16]$.

The calculations of H. L. Davis [8], by the KorringaKohn-Rostoker method seem to be a reasonable approach of the band structure of this compound. These calculations are non self-consistent, non relativistic (spin-orbit coupling on 5f states is about $0.7 \mathrm{eV}$ [17]), and neglect the strong correlations between $5 \mathrm{f}$ electrons. However, the results are in qualitative agreement with experimental observations, especially photoemission [9]. One can therefore propose the following band scheme (see Fig. 1) :

- US has a metallic conductivity.

- There is a full band about $4 \mathrm{eV}$ wide containing 6 states mostly from the sulphur $3 p$ shell but showing some $6 \mathrm{~d}-5 \mathrm{f}$ character on the uranium site. This gives rise to the covalent character of the compound.

- There is a full band at low energy containing the 3s states of sulphur which play little role in the bonding.

- The uranium $7 \mathrm{~s}$ band is nearly empty.

- The conduction bands are mostly formed with very hybridized $6 \mathrm{~d}$ and $5 f$ uranium states : the density of states at the Fermi level is thus very high. The occupation number of the $5 \mathrm{f}$ states is between 2 and 3 .

It is interesting to compare the $5 \mathrm{f}$ band width calculated by Davis on US $(E>1 \mathrm{eV})$ with the $4 \mathrm{f}$ band width that the same author has calculated by the
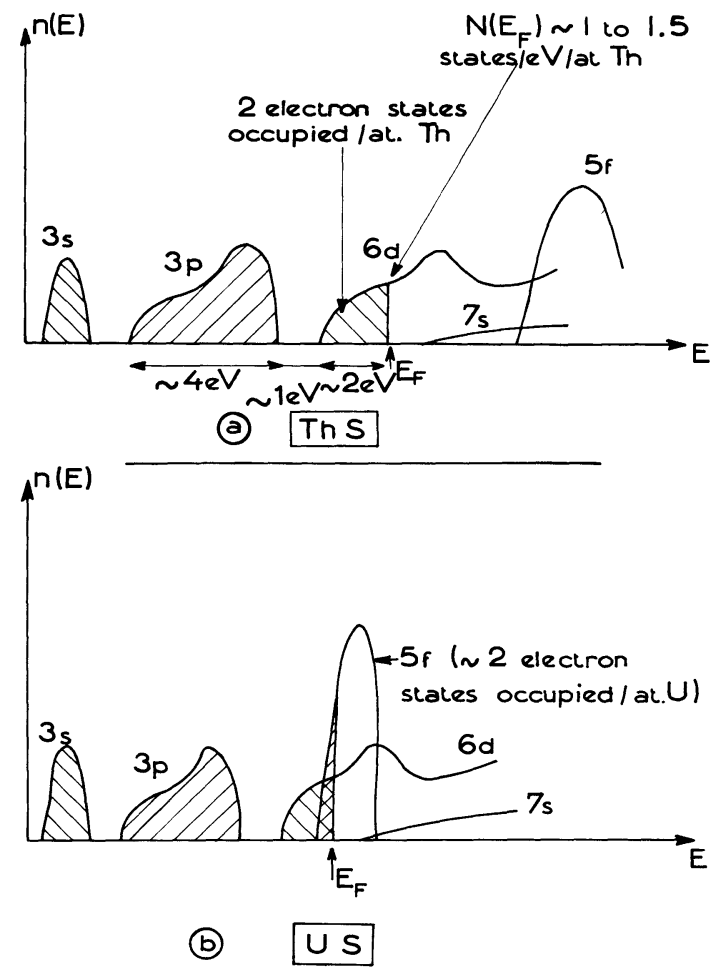

FIG. 1. - Schematic band structure of ThS and US.

same method for samarium and gadolinium compounds $(E \simeq 0.05 \mathrm{eV})$ [18] : the difference is partly due to the greater radial extent of the $5 f$ wave function, but also to the fact that the $5 f$ states have the same energy as the $6 \mathrm{~d}, 7 \mathrm{~s}$ and $3 \mathrm{p}$, favouring an enlargement by hybridization.

Of course these band calculations neglect the interatomic Coulomb correlations which tend to maintain an integer occupation number of $5 \mathrm{f}$ electrons on each uranium site. This was discussed in the case of the uranium carbides and nitrides [19]. As for these compounds, it seems that the real description is half way between the two conventional ones : localized $5 f$ electrons and itinerant 5 f electrons.

The thorium sulphide band structure must have great resemblance to the US one, with the exception that the $5 \mathrm{f}$ states are unoccupied. In $\mathrm{ThS}$, the absence of $5 f$ states at the Fermi level is confirmed by the small value of the magnetic susceptibility $\left(32 \times 10^{-6}\right.$ emu/mole [3]) and of the electronic specific heat [14, 20] which corresponds to an apparent density of states at the Fermi level of 0.8 states/eV/Th atom/spin (1.6 per Th atom). One can then propose for $\mathrm{ThS}$ a band structure (see Fig. 1) which is consistent with the transport properties :

- The Hall constant (B. Griveau, 1971, unpublished) corrected for porosity is at $300 \mathrm{~K}$ :

$$
R_{\mathrm{H}}=1.6( \pm 0.2) \cdot 10^{-10} \mathrm{~m}^{3} / \text { coulomb }
$$

from this value one calculates in a free-electron model a number $n_{\mathrm{e}}=1.8 \pm 0.2$ electrons per thorium atom.

- The electrical resistivity $[2,15]$ has a metallic 
character and increases linearly between 100 and $1000 \mathrm{~K}$.

- The thermoelectric power [2] is negative and varies nearly linearly between 300 and $1000 \mathrm{~K}$. By applying the formula of Mott and Jones (ref. [21] p. 311) for a parabolic density of states and an electronic relaxation time independent of energy, one calculates a Fermi energy of $3 \mathrm{eV}$. From this value and assuming two electron states per Th atom occupied in the band, the density of states at the Fermi level is 0.5 states/eV/Th atom/spin, roughly consistent with specific heat data $[14,20]$.

2. 2 NUMBER OF $5 f$ ELECTRONS. - In the actinide sulphides (with the exception of ThS), the number of $5 \mathrm{f}$ electrons per metal atom is not known and cannot be simply determined by magnetic measurements because the crystal field effects and the 5f-6d hybridization modify the free ion magnetic moment value considerably : for US, the configurations $5 \mathrm{f}^{1}$ [12], $5 \mathrm{f}^{2}$ [6], and even $5 \mathrm{f}^{4}$ [23] have been proposed (see compilation by Kuznietz [24]). The existence of the $5 \mathrm{f}^{4}$ configuration seems unlikely because the valence 2 has never been encountered in the uranium ionic compounds.

In a study of the magnetic form factor of US by neutron scattering, Wedgwood [5] has shown that the best fit with the experimental results is given by a $5 \mathrm{f}^{2}$ configuration with combined crystal field and exchange field effects, as suggested by GrunzweigGenossar et al. [6]. However this study only tested a limited number of simple localized models.

Another estimation of the effective valence can be made by analyzing the value of the lattice parameter. Using ionic radii as they justified for rare earth monosulphides (despite the metallic conductivity), Allbutt and Dell [25] and Grunzweig-Genossar et al. [6] find a valence near 4 for $U$ in US.

In conclusion, it seems reasonable to estimate the $5 f$ occupation number as being $2 \pm 0.5$. This value may be fractional as shown by the irregular variation of the lattice parameters with the atomic number from ThS to AmS [26, 27], similar to that of the carbides and nitrides [28]. Fractional 5f occupation numbers (due to narrow bands or virtual bound states or interconfiguration fluctuations) have already been suggested by Fisk and Coles [12] for the $\mathrm{U}\left(\mathrm{P}_{1-x} \mathrm{~S}_{x}\right)$ and $\left(\mathrm{U}_{x} \mathrm{Th}_{1-x}\right) \mathrm{S}$ solid solutions, and by de Novion and Costa [19] for $\mathrm{U}\left(\mathrm{C}_{1-x} \mathrm{~N}_{x}\right)$.

2.3 ELECTRONIC PROPERTIES OF URANIUM MONOSULPHIDE US. - 2.3.1 Magnetic properties. Below its Curie temperature (178 K [4]), US is a simple ferromagnet. The para-ferromagnetic transition is probably of the 2nd kind and is followed by a rhombohedral distortion [29], magnetodilatation [29], and anomalies of specific heat [7], electrical resistivity [15, 30-32] and thermoelectric power [31].

In the ferromagnetic state the moments, localized on the uranium ion, are parallel to the $\langle 111\rangle$ axis of the rhombohedral cell. Their value $\left(1.70 \pm 0.03 \mu_{\mathrm{B}}\right.$ [33]), measured by neutron scattering on a single crystal is bigger than that calculated from the magnetization curves, obtained by applying the magnetic field parallel to the easy magnetization direction of the same single crystal : $1.55 \mu_{\mathrm{B}}$ [34]. The difference of $0.15 \mu_{\mathrm{B}}$ has been attributed to a polarization of the conduction electrons. The moment on the sulphur ion is smaller than $0.02 \mu_{\mathrm{B}}$ [33]. The magnetic anisotropy is very high $(250 \mathrm{kOe}[34])$. The ordered moments measured on powders using magnetic fields smaller than $10 \mathrm{kOe}$ are small $[32,47]$, due to coercive field and anisotropy (see $\S 5$ ).

The magnetic susceptibility above $200 \mathrm{~K}$ obeys a Curie-Weiss law :

$$
\chi=\chi_{0}+\frac{C}{T-\theta_{\mathrm{p}}} \quad \text { where } \quad C=\frac{N p^{2} \mu_{\mathrm{B}}^{2}}{3 K_{\mathrm{B}}}
$$

with

$$
\begin{aligned}
-\chi_{0} & =0, \theta_{\mathrm{p}}=173 \mathrm{~K}, p=2.25 \mu_{\mathrm{B}}(200-300 \mathrm{~K})[4], \\
-\chi_{0} & =245 \times 10^{-6} \mathrm{emu} / \mathrm{mole}, \theta_{\mathrm{p}}=180 \mathrm{~K}, \\
p & =2.31 \mu_{\mathrm{B}}(200-1000 \mathrm{~K})[35], \\
-\chi_{0} & =0, \theta_{\mathrm{p}}=185 \mathrm{~K}, p=2.22 \mu_{\mathrm{B}}(200-300 \mathrm{~K})[36] .
\end{aligned}
$$

The hyperfine field at the uranium nucleus in ferromagnetic US has been measured at $4.2 \mathrm{~K}$ by ${ }^{238} \mathrm{U}$ Mössbauer spectroscopy; it unfortunately cannot distinguish between $5 \mathrm{f}^{2}$ and $5 \mathrm{f}^{3}$ configurations [22].

2.3.2 Transport properties. - The electrical resistivity [15, 30-32], thermoelectric power [31] and Hall effect [32] depend mostly on the magnetic behaviour of US and cannot easily be related to the band structure.

The positive Hall constant measured by Griveau (1971, unpublished) between 320 and $550 \mathrm{~K}$, can be analyzed in the following form, theoretically justified for ferromagnets [37] :

$$
R_{\mathrm{H}}(T)=R_{0}+R_{1} \rho^{2}(T) \chi(T),
$$

where $\rho$ is the electrical resistivity of the same sample [15], and $\chi$ the magnetic susceptibility [35]. The extraordinary Hall effect, characterized by $R_{1}$ is predominant. The ordinary Hall constant, negative and independent of temperature is :

$$
R_{0}=2.3( \pm 0.5) 10^{-10} \mathrm{~m}^{3} / \text { coulomb }
$$

from which one calculates a number $n_{\mathrm{e}}=1.25 \pm 0.25$ of conduction electrons per uranium atom; this value roughly confirms the estimation of the valence made in $\S 2.2$.

2.3.3 Specific heat. - This has been measured between 1.5 and $10 \mathrm{~K}$ by Westrum et al. [7] who calculate a coefficient $\gamma=23.4 \mathrm{~mJ} / \mathrm{mole} / \mathrm{K}^{2}$ for the electronic specific heat, leading to a density of states at the Fermi level of 4.58 states/eV/U atom/spin.

At high temperature $(500-600 \mathrm{~K})$, the analysis of 
the specific heat at constant pressure [38, 39], corrected for dilatation [40], gives a much. smaller apparent density of states at the Fermi level : 1.8 states/eV/U atom/spin at the most.

Although one has probably at low temperature to take into account a large enhancement of the effective mass by the many-body interactions (especially exchange and electron-phonon which are known to vanish at high temperature), this result is consistent with the existence of narrow $5 f-6 d$ bands at the Fermi level (cf. $\S 2.1$ ).

2.3.4 Models. - Although most of the theoretical and experimental work seems to show that the $5 \mathrm{f}$ states are band-like in US, the results have been generally analyzed in terms of localized models.

Flotow et al. [20] estimate a magnetic entropy which is not far from the value given by a 3-fold degenerate level $(R \ln 3=9.13 \mathrm{~J} / \mathrm{K} / \mathrm{mole})$. In spite of the uncertainties due to the comparison method used, the order of magnitude of this entropy seems correct, and shows that the magnetic behaviour is not that of free ions $\mathrm{U}^{2+}, \mathrm{U}^{3+}, \mathrm{U}^{4+}$ or $\mathrm{U}^{5+}$, but that the crystal field effects raise the degeneracy of the free ion energy levels considerably $\left(\Delta E \gg 10^{-2} \mathrm{eV}\right)$.

Gardner and Smith [34] have analyzed the magnetic properties of US assuming a $5 \mathrm{f}^{4}$ configuration $(J=4)$. In the Russel-Saunders approximation, neglecting the 6th order terms of the crystal field, the fundamental level is a triplet $\Gamma_{5}$ and gives magnetic moments and entropy in good agreement with those observed.

On the other hand, Grunzweig-Genossar et al. [6] have supposed a $5 f^{2}(J=4)$ configuration : the fundamental level is a singlet $\Gamma_{1}$, and the first excited one a triplet $\Gamma_{4}$. The magnetic order is induced at low temperature when the exchange field is bigger than the crystal field. From the knowledge of the Curie temperature and of the ordered moment, they deduce the energy of the excited levels $\left(\Gamma_{4}\right.$ is at $430 \mathrm{~K}$ from $\left.\Gamma_{1}\right)$ and the value of the exchange field. These values are consistent with the magnetic entropy [41].

If one compares these two localized models, it is obvious that the $5 \mathrm{f}^{2}$ model predicts excited levels of the uranium ion between 400 and $1100 \mathrm{~K}$; these should give rise to departures from the Curie-Weiss law which are not observed [35]. On the other hand the $5 \mathrm{f}^{4}$ model is in contradiction with the analysis of interatomic distance (cf. $\S 2.2$ ) and with the values of the aspherical components of the neutron scattering magnetic form factor [5].

2.4 Previous Results ON MIXed $\left(\mathrm{U}_{x} \mathrm{Th}_{1-x}\right) \mathrm{S}$ MONOSULPHIDES. - The magnetic susceptibility results of Griveau et al. [15] have shown that the paramagnetic moment per uranium atom remains constant $\left(2.3 \mu_{\mathrm{B}}\right)$ for $x=0.8$ and 0.6. This value is also found in the dilute uranium region $(x \leqslant 0.15)$ [44].

The Curie temperature determined from magnetic susceptibility and electrical resistivity measure- ments [15] (see Fig. 9) decreased with uranium concentration and vanished for a critical composition $x_{\mathrm{c}}$ between 0.4 and 0.6. The paramagnetic Curie temperature $\theta_{\mathrm{p}}$ became largely negative for $x=0.4$ and 0.2 . For these two compositions field dependence, observed below $180 \mathrm{~K}$ and probably due to clusters or inhomogeneities, did not allow Griveau et al. [15] to obtain precise magnetic susceptibility curves.

3. Experimental procedures. - 3.1 MAGnetizATION MEASUREMENTS. - They have been made in the laboratory of Dr. Fruchart at Vitry s/Seine (C.N.R.S.) by an inductive method (cf. ref. [42], p. 60). The precision of the measured magnetization is $0.5 \%$, but the reproducibility of the measurements is only $1 \%$. The precision of the temperature, measured by a copper-constantan thermocouple, is of the order of $1 \mathrm{~K}$.

The magnetic field $H$, after demagnetization field and image effect corrections is known with a precision of $1 \%$.

The sample, in powder form is enclosed in an ellipsoidal sample holder, the magnetization of which is determined previously.

3.2 SPECIFIC HEAT MEASUREMENTS. - They were made in an adiabatic calorimeter, described in the reference [40]. At very low temperature (1.5-100 K) the precision is about $1 \%$; at higher temperature $(100-300 \mathrm{~K})$ it is somewhat less $(2$ to $3 \%)$.

3.3 ElASTIC NEUTRON SCATTERING EXPERIMENTS. Powder neutron diffraction measurements were made on diffractometers at A.E.R.E., Harwell to determine the ordered $5 f$ shell moment. This sort of experiment is described in detail for the case of ferromagnetic UTe by Wedgwood and Kuznietz [33]. Two scans are made, one above and one below the Curie temperature. The high temperature scan is used to characterize the sample and measure precise composition and Debye-Waller factors. In the low temperature scan, there is an additional intensity in low angle Bragg peaks and after subtraction of the calculated nuclear scattering the magnetic structure factor can be found. The PANDA spectrometer, which gives good resolution to high angles, was used for the high temperature runs since this gave a large number of well resolved Bragg peaks for the crystallographic least squares refinement. The CURRAN spectrometer, which gives high intensity but poorer high angle resolution, was used for the low temperature runs where good statistical accuracy was necessary to separate the relatively small magnetic scattering from the nuclear scattering.

3.4 INELASTIC NEUTRON SCATTERING EXPERIMENTS. - They were made using a time of-flight spectrometer at Harwell. This gives the optical phonon frequencies as shown by Wedgwood [43]. These frequencies are used for calculating the Einstein specific heat contri- 
bution to the specific heat (cf. § 9.2). In addition there is qualitative information about possible magnetic crystal field levels.

4. Characterization of the samples. - The samples with uranium atomic content $x=0,0.42,0.61$ and 0.82 were prepared by reduction of $\mathrm{US}_{2}$ and $\mathrm{ThS}_{2}$ by the metals, and annealing under vacuum at $1800^{\circ} \mathrm{C}$. Details on the preparation method may be found in the paper by Griveau et al. [15].

The dependence of the lattice parameter with composition, as measured by these authors (see table I) nearly follows Vegard's law, and is quite different from those obtained by Chechernikov et $a l$. [13]. The results of the latter authors are probably due to a change in the $\mathrm{U} /(\mathrm{U}+\mathrm{Th})$ ratio during the treatment at very high temperature [15]. The uranium to thorium atomic ratio were determined by electron microprobe analysis which also confirmed the homogeneity of the alloys on a scale of $10^{-4} \mathrm{~cm}$.

\section{TABLE I}

Lattice parameters a of $\left(\mathrm{U}_{x} \mathrm{Th}_{1-x}\right) \mathrm{S}$ (a is given with a precision of $\pm 10^{-3} \AA$ )

\begin{tabular}{|c|c|c|c|c|c|c|c|}
\hline$x$ & ThS & 0.25 & 0.42 & 0.44 & 0.61 & 0.82 & 1.00 \\
\hline$\overline{a(\AA)}$ & 5683 & $\overline{5637}$ & $\overline{5608}$ & $\overline{5.605}$ & $\overline{5573}$ & 5.527 & 5488 \\
\hline
\end{tabular}

The analysis of our neutron diffraction measurements (cf. § 6) indicates an apparent non stoichiometry in the form $(\mathrm{U}, \mathrm{Th})_{0.95} \mathrm{~S}$. We made a chemical analysis of the sulphur content and found

$$
\mathrm{S} /(\mathrm{U}+\mathrm{Th})=0.97 \pm 0.01
$$

(atomic ratio). The contradiction can be explained assuming 3\% carbon atoms dissolved in the sulphur lattice because the neutron scattering length of $\mathrm{C}$ is much greater than that of $\mathrm{S}$. Effectively, chemical analysis of the carbon content in $\left(\mathrm{U}_{0.6} \mathrm{Th}_{0.4}\right) \mathrm{S}$ gave $1190 \pm 100 \mathrm{ppm}$ weight $(2.65 \pm 0.25 \%$ atomic $)$. This carbon could originate from oil of the vacuum pump. The solubility of UC in US is known to be about $40 \%$ (atomic) [45]. The nitrogen content is small $(\mathrm{N} / \mathrm{S} \simeq 0.3 \%$ atomic) [15] and most of the oxygen is present in a $2 \%$ ThOS second phase as determined by X-ray [15] and neutron diffraction.

The two samples of $U /(U+T h)$ ratio $x=0.44$ and $x=0.25$ (see specific heat measurements) were prepared later by solid state diffusion $\left(1800^{\circ} \mathrm{C}\right)$ of $\mathrm{ThS}$ and $\left(\mathrm{U}_{0.61} \mathrm{Th}_{0.39}\right) \mathrm{S}:$ their chemical analysis was about the same as for the preceding samples but the homogeneity was not quite so good. The lattice parameters are given in table I.

5. Magnetization measurements. - These have been made on the uranium monosulphide US and the three mixed samples $\left(\mathrm{U}_{0.82} \mathrm{Th}_{0.18}\right) \mathrm{S},\left(\mathrm{U}_{0.61} \mathrm{Th}_{0.39}\right) \mathrm{S}$, $\left(\mathrm{U}_{0.42} \mathrm{Th}_{0.58}\right) \mathrm{S}$.

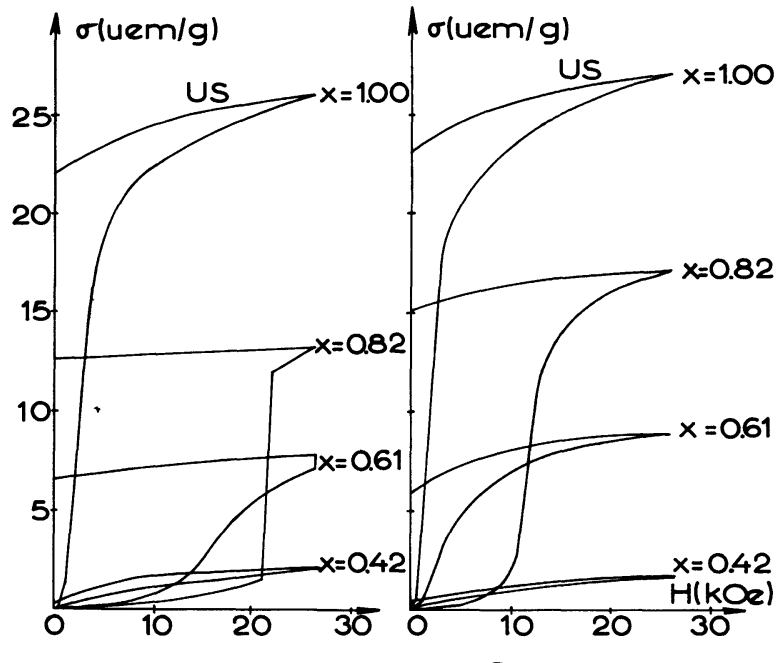

(a) $4.2 \mathrm{~K}$

(b) $20.4 \mathrm{~K}$

FIG. 2. - Magnetization $\sigma$ of the mixed sulphides $\left(\mathrm{U}_{x} \mathrm{Th}_{1-x}\right) \mathrm{S}$ vs applied magnetic field at 4.2 and $20.4 \mathrm{~K}$.

We have reported in figure 2 the magnetization curves of these four compounds at 4.2 and $20.4 \mathrm{~K}$. The curves have been obtained by the following procedure : first the samples were cooled outside the external field $H$; next, magnetization was measured at increasing fields up to $26.6 \mathrm{kOe}$, then at decreasing fields to $0 \mathrm{Oe}$. This procedure explains the high value of the observed hysteresis.

These curves show that the three uranium rich compounds $(x=1,0.82,0.61)$ are ferromagnetic at 4 and $20 \mathrm{~K}$, as is confirmed by neutron scattering (cf. § 6) and by the preceding study of Griveau et al. [15]. On the contrary, the compound $\left(\mathrm{U}_{0.42} \mathrm{Th}_{0.58}\right) \mathrm{S}$ shows no resistivity anomaly [15] and probably no long range ferromagnetic order at low temperature. The small remanent magnetization observed at $4 \mathrm{~K}\left(\simeq 0.02 \mu_{\mathrm{B}} /\right.$ metal atom $)$ is probably associated with ferromagnetic clusters.

5.1 The COERCIVE FIELD. - For the three ferromagnetic samples, one can estimate roughly from the data at $4.2 \mathrm{~K}$, a coercive field $H_{\mathrm{c}}$ : approximately $4 \mathrm{kOE}$ for US, 22 for $x=0.82$ and 18 for $x=0.61$. It is difficult to know whether the origin of this strong coercive field is due to anisotropy or anchoring of Bloch walls. This is because, due to the small grain size $(\simeq 10 \mu)$ of our samples, we do not know if the grains are single domains or contain several Bloch domains.

5.2 The Saturation magnetic moments. - The maximum magnetization per metal atom measured on our samples is reported in table II. For the three ferromagnetic samples, this is measured at $26.6 \mathrm{kOe}$ and $20 \mathrm{~K}$, because at this temperature the coercive field is smaller than at $4 \mathrm{~K}$.

To obtain the saturation magnetization from the 
TABLE II

Estimation of the saturation magnetic moments at $0 \mathrm{~K}$ in $\left(\mathrm{U}_{x} \mathrm{Th}_{1-x}\right) \mathrm{S}$ by magnetization measurements

\author{
Sample \\ Maximum measured magne- \\ tization $\left(\mu_{\mathrm{B}} /\right.$ metal atom) \\ Estimated saturation mo- \\ ment at $0 \mathrm{~K}\left(\mu_{\mathrm{B}} /\right.$ metal \\ atom)
}

Estimated saturation moment at $0 \mathrm{~K}\left(\mu_{\mathrm{B}} /\right.$ uranium atom)
US
1.31
1.59
(powder)
1.55
(single
crystal)
1.59
(powder)
1.55
(single
crystal)

measured curves at $20.4 \mathrm{~K}$ (Fig. 2), we have used the following procedure :

- Subtraction of a high field magnetization $\chi \mathrm{H}$, where $\chi=14 \times 10^{-6} x$ (emu.cgs/g), $x$ being the atomic ratio $U /(U+T h)$. This magnetization was determined experimentally at $x=1$ by Gardner and Smith [34].

- Extrapolation to zero temperature, assuming that the saturation magnetizations follow a same law $M=M_{0} f\left(T / T_{\mathrm{c}}\right)$, where $M_{0}$ is the saturation magnetization at $0 \mathrm{~K}, T_{\mathrm{c}}$ the Curie temperature, $f$ a function determined experimentally on US [34]. Between 20 and $0 \mathrm{~K}$, the correction is smaller than $1 \%$ for US, of the order of $1 \%$ for $x=0.82$ and $3 \%$ for $x=0.61$.

- Extrapolation to infinite external field. This third correction is rather difficult for a polycrystal such as US where the $\langle 111\rangle$ anisotropy field is very large, about $250 \mathrm{kOe}$ [34]. In this case, above the coercive field $H_{\mathrm{c}}$, the magnetization state consists of domains magnetized along the nearest $\langle 111\rangle$ axis to the field direction, and one calculates a bulk magnetization which is $86 \%$ of the saturation value [46]. We have thus divided our data by 0.86 .

The saturation magnetic moments, obtained after making the three corrections described above, are given in table II. The validity of our procedure is shown by the moment value for US, $1.59 \mu_{\mathrm{B}}$, which is quite near that measured by Gardner on the easy magnetization axis of a single crystal [34]. The moments of the mixed sulphides could be slightly underestimated : for $x=0.82$ because of the strong coercive field, and for $x=0.61$ because the ferroparamagnetic transition is rather spread in temperature, and the decrease of magnetization between 0 and $20 \mathrm{~K}$ is probably bigger than the $3 \%$ estimated above. In any case, for both samples, the error must be smaller than $5 \%$.

5.3 CURIE TEMPERATURES. - We show in figure : the temperature dependence of magnetization mea-

$\begin{array}{ccc}x=0.82 & x=0.61 & x=0.42 \\ 0.83 & - & - \\ 1.05 \pm 0.05 & 0.56 \pm 0.03 & 0.10 \\ 1.28 \pm 0.06 & \\ & 0.92 \pm 0.05\end{array}$

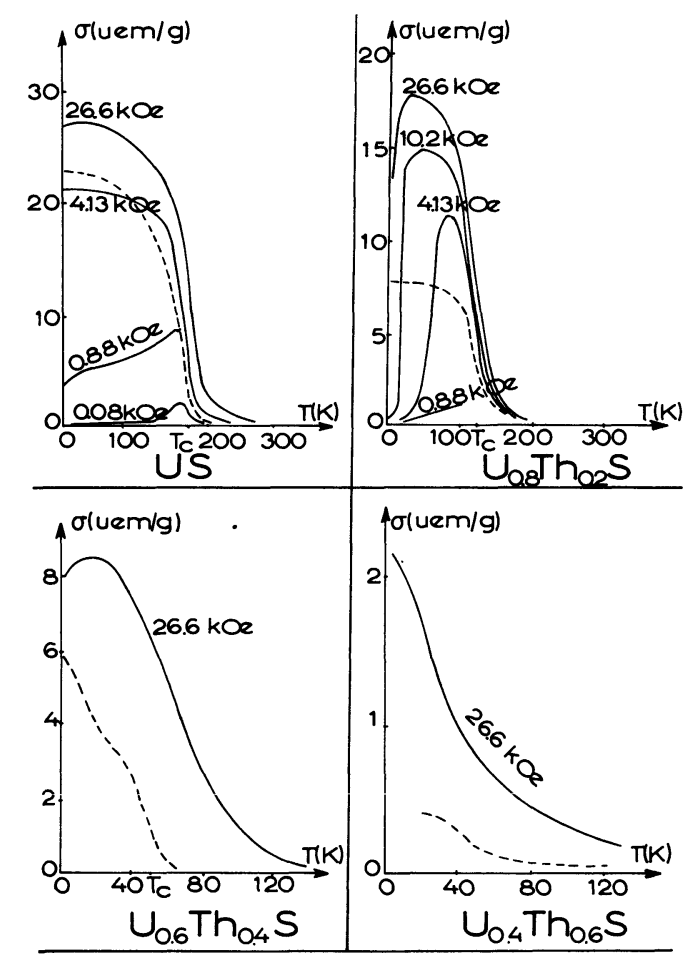

FIG. 3. - Dependence of the magnetization $\sigma$ of the mixed sulphides $\left(\mathrm{U}_{x} \mathrm{Th}_{1-x}\right) \mathrm{S}$ with temperature at several applied magnetic fields.

sured at several external magnetic fields up to $26.6 \mathrm{kOe}$.

The full curves have been obtained at constant field and increasing temperatures after cooling the sample out of the field. This procedure explains the shape of the curves [42] : around the temperature where the coercive field becomes smaller than the applied magnetic field, one observes a maximum of magnetization.

The dotted curves of figure 3 have been obtained by a different procedure : cooling of the sample to $4 \mathrm{~K}$ in small magnetic field $(\simeq 80 \mathrm{O})$, then measurement at increasing temperatures for this value of the applied 
TABLE III

$\begin{array}{cr}\text { Sample } & T_{\mathrm{c}} \text { (magnetizati } \\ - & (\mathrm{K}) \\ \mathrm{US} & -173 \\ x=0.82 & 121 \pm 2 \\ x=0.61 & 52 \pm \\ x=0.44 & \\ x=0.42 & \end{array}$

field. In this case most of the domains are favourably oriented, and the magnetization maxima disappear.

The Curie temperatures have been calculated from these remanent magnetization curves, as the intersection of the inflexion tangent of $\sigma^{2}(T)$ with the temperature axis [48]. They are reported in table III, together with the values obtained from electrical resistivity $[15,30]$ and specific heat measurements $[7$, 14] (seé also $\S 9$ ).

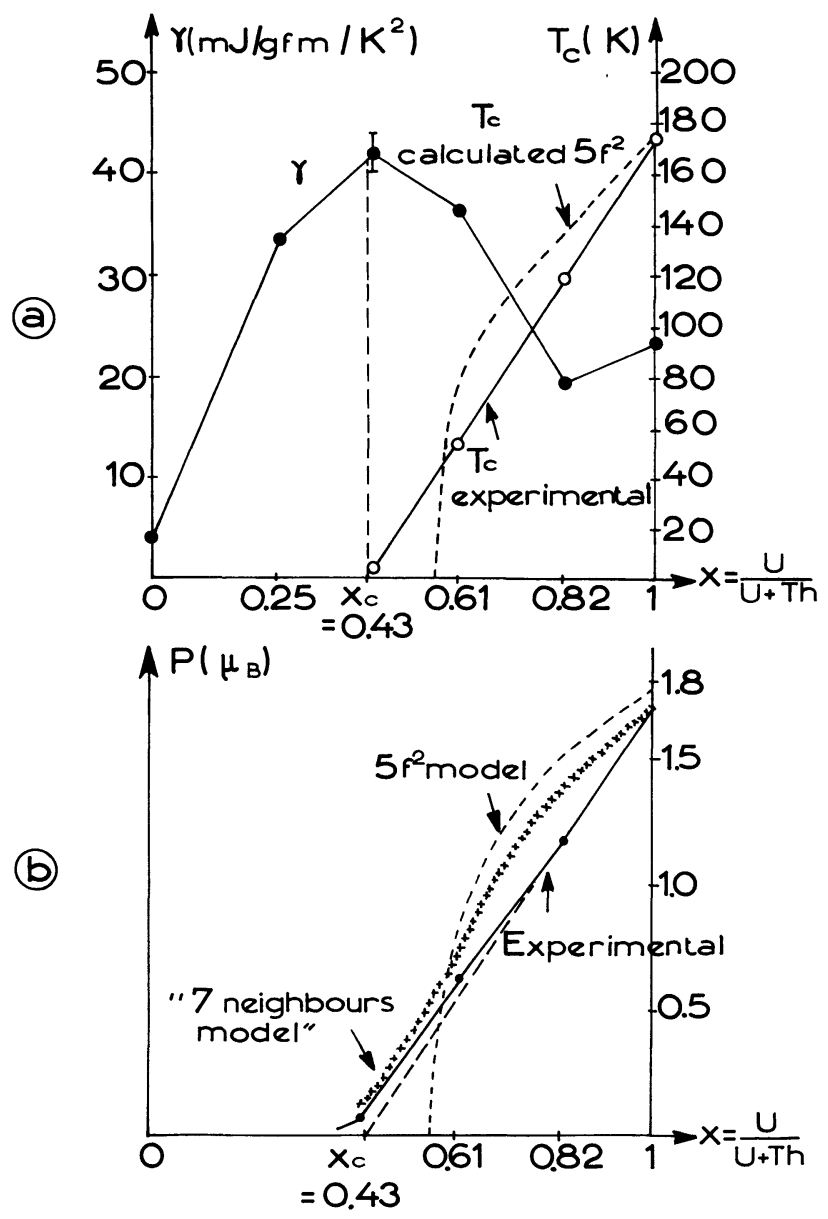

FIG. 4. - Dependence with the ratio $\mathrm{U} /(\mathrm{U}+\mathrm{Th})$ of $: a)$ The $\gamma$ coefficient of low temperature electronic specific heat. The Curie temperature $T_{\mathbf{C}}$ compared with the calculated values within the localised $5 \mathrm{f}^{2}$ model. b) The ordered magnetic moment at $0 \mathrm{~K}$ per metal atom compared with the values calculated within the localised $5 \mathrm{f}^{2}$ model and within the model where the only uranium having a magnetic moment $\left(1.7 \mu_{\mathrm{B}}\right)$ are those with at least 7 uranium first neighbours.

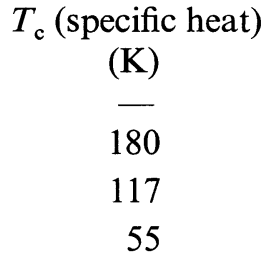

$4.5(?)$

No Curie point

The curve showing the dependence of Curie temperature with uranium content $x$ is given in figure 4 : in first approximation it varies linearly with $x$, as does the bulk magnetization (cf. table II). The critical composition for ferromagnetism is approximately $\left(\mathrm{U}_{0.43} \mathrm{Th}_{0.57}\right) \mathrm{S}$.

6. Neutron elastic scattering. - 6.1 EXPERIMENTAL RESULTS. - ThS. The results of two powder neutron diffraction scans at $4.2 \mathrm{~K}$ are summarized in table IV. The second one was done at higher resolution and is the more accurate. The scattering length of the thorium atoms was low compared to its value in the literature [49] and lead to an apparent composition $\mathrm{Th}_{0.94} \mathrm{~S}$. This was largely due to the substitutional impurities in the sulphur lattice, especially carbon (see $\S 4$ ). When correction was made for carbon and nitrogen content, the apparent metal deficiency was reduced to $1.3 \%$. Correction for oxygen content was not made, because most of it is in a ThOS second phase (see $\S 4$ ). The average measured Debye-Waller factors are 0.23 and $0.65 \AA^{2}$ for the thorium and sulphur atoms respectively and their ratio 2.83 is close to the root mass ratio $\sqrt{M_{\mathrm{Th}} / M_{\mathrm{S}}}=2.73$ expected from lattice dynamics at absolute zero [50]. Since the Debye and Einstein temperatures for the solid solutions are nearly independent of concentration (table VI), we have assumed that the low temperature Debye-Waller factors of the mixed compounds are the same as those of $\mathrm{ThS}$.

$\left(\mathrm{U}_{0.61} \mathrm{Th}_{0.39}\right) \mathrm{S}$. Two powder diffraction runs were done at room temperature to determine the mean metal atom scattering length. The results of least squares analysis of the data are shown in the second part of table IV where the refined parameters are mean metal atom scattering length and Debye-Waller factors. As in the case of $\mathrm{ThS}$, the apparent mean metal scattering length was found to be less than the theoretical one, leading to a metal atom deficiency of $1.5 \%$ after correction for $\mathrm{C}$ and $\mathrm{N}$ impurities.

To measure the $5 f$ magnetic moment the (111) and (200) reflections were measured at $4.2 \mathrm{~K}$. Since the magnetic scattering is relatively weak the ratio $I_{(111)} / I_{(200)}$ is only different by about $6 \%$ from the ratio due purely to nuclear scattering, so it is necessary to measure this ratio very accurately. The estimated 


\section{TABLE IV}

Summary of neutron elastic scattering data. Estimation of saturation magnetic moments at $0 \mathrm{~K}$ in $\left(\mathrm{U}_{x} \mathrm{Th}_{1-x}\right) \mathrm{S}$ by neutron diffraction measurements

ThS $(4.2 \mathrm{~K})$

Number of reflections measured

$R$, agreement factor $\%$

$B_{\mathrm{Th}}$ Debye-Waller factor

$B_{\mathrm{S}}$ Debye-Waller factor

$b_{\mathrm{Th}}$ apparent thorium scattering length $\left(\mathrm{cm} \times 10^{-12}\right)$

$b_{\mathrm{Th}}$ after correction for $\mathrm{C}$ and $\mathrm{N}$ impurities

$b_{\mathrm{Th}}$ (Willis, ref. [49])

$\mathrm{U}_{0.61} \mathrm{Th}_{0.39} \mathrm{~S}(300 \mathrm{~K})$

Number of reflections measured

$R$, agreement factor $\%$

$B_{\text {metal }}$ Debye-Waller factor

$B_{\mathrm{S}}$ Debye-Waller factor

$b_{\text {metal }}$ apparent mean metal atom scattering length $\left(\mathrm{cm} \times 10^{-12}\right)$

$b_{\text {metal }}$ after correction for $\mathrm{C}$ and $\mathrm{N}$ impurities

$b_{\text {metal }}$ theoretical for stoichiometric compound

$I_{(200)} / I_{(111)}$ at $4.2 \mathrm{~K}$ average of 6 runs

Moment per cation $\left(\mu_{\mathrm{B}}\right)$

$\mathrm{U}_{0.82} \mathrm{Th}_{0.18} \mathrm{~S}(300 \mathrm{~K})$

Number of reflections measured

$R$, agreement factor $\%$

$B_{\text {metal }}$ Debye-Waller factor

$B_{\mathrm{S}}$ Debye-Waller factor

$b_{\text {metal }}$ apparent mean metal atom scattering length $\left(\mathrm{cm} \times 10^{-12}\right)$

$b_{\text {metal }}$ after correction for $\mathrm{C}$ and $\mathrm{N}$ impurities

$b_{\text {metal }}$ theoretical for stoichiometric compound

$I_{(200)} / I_{(111)}$ at $4.2 \mathrm{~K}$ average for 3 runs

Moment per metal atom $\left(\mu_{\mathbf{B}}\right)$

\section{Run 1}

9

1.37

0.47

0.48

0.967

1.008

3.07

0.52

0.71

0.846

0.882

1.28

0.59

0.72

0.825

0.860
Run 2

14

0.76

0.16

0.70

0.915

0.954

13

1.76

0.69

0.92

0.858

0.894

Average

0.65

0.938

0.978

0.99

0.60

0.80

0.851

0.887

0.900

2.069

$0.9 \pm 0.3$

8

1.34

0.40

0.48

0.55

0.66

0.829

0.827

0.862

0.870

1.984

$1.3 \pm 0.3$

error in the measured ratio after six runs was less than $1 \%$. From this ratio, using the mean metal atom scattering length from the room temperature runs and assuming the magnetic form factor to be the same as in US [5], we calculate the mean metal atom magnetic moment to be $0.9 \pm 0.3 \mu_{\mathrm{B}}$. The main error comes from the uncertainty in the mean metal atom scattering length.

$\left(\mathrm{U}_{0.82} \mathrm{Th}_{0.18}\right) \mathrm{S}$. This experiment was very similar to the $61 \%$ uranium one except that the mean magnetic moment is greater, so that higher fractional accuracy is easier to achieve. The metal atom deficiency is $0.9 \%$ and the mean metal magnetic moment is $1.3 \pm 0.3 \mu_{\mathrm{B}}$.

6.2 COMParison WITH BULK MAgNETIZATION RESULTS. - It is important to appreciate that the neutron diffraction method measures the $5 \mathrm{f}$ moment per metal atom whereas the bulk magnetization method measures the total moment per formula unit. In the case of US the $5 f$ moment is $1.7 \mu_{\mathbf{B}}$ [5] whereas the total moment is $1.55 \mu_{\mathrm{B}}$ [34] and the difference is ascribed to negative conduction electron polarization. We have assumed that this polarization is proportional to the magnetization in the mixed compounds and have corrected the bulk moments accordingly. These and the neutron results are shown in figure $4 b$; although they are the same within the error bars, the neutron results seem systematically higher. The reason why the bulk results may be low was detailed in $\S 5.2$. Also any inhomogeneity in the mixtures would cause the neutron results to be high since the measured quantity is proportional to the square of the ordered magnetic moments.

7. Analysis of the magnetic behaviour of $\left(U_{x} T_{1-x}\right) S$. - The magnetic susceptibility measurements of $\left(\mathrm{U}_{x} \mathrm{Th}_{1-x}\right) \mathrm{S}$ with low uranium concentration (1 to $15 \%$ ) [44] follow a Curie-Weiss law

$$
\chi=\chi_{0}+C /\left(T+\theta_{\mathrm{p}}\right)
$$

with a large $\theta_{\mathrm{p}}(\simeq 150 \mathrm{~K})$ rather than a Curie law $C / T$ 
characteristic of dilute localized moments : this suggests that the fundamental state of an uranium atom dissolved in $\mathrm{ThS}$ is non magnetic.

This hypothesis is somewhat confirmed by the absence of long-range magnetic order for $x<0.43$; indeed, if there were ferromagnetic interactions between uranium first neighbours only, all of them with an identical localized moment, the critical uranium concentration for long-range ferromagnetism should be around $0.15[51,52]$. The $5 \mathrm{f}^{4}$ localized model, predicting a magnetic fundamental level $\Gamma^{5}$ (see $\S 2.3 .4$ ) is thus unlikely. Hence, the discussion will be restricted to the $5 \mathrm{f}^{2}$ localized model where the octahedral crystal field quenches the total moment of the $\mathrm{U}^{4+}$ ion, and to the possibility of itinerant $5 \mathrm{f}$ electrons.

7.1 LOCALIZED $5 \mathrm{f}^{2}$ MODEL. - We have compared our magnetization results with the model of Grunzweig-Genossar et al. [6] simplified by taking only into account the fundamental singlet $\left|\Gamma_{1}\right\rangle$ and the first excited triplet $\left|\Gamma_{4}\right\rangle$, the exchange field being oriented along the $\langle 111\rangle$ axis of the crystal.

Choosing the $\langle 111\rangle$ axis of the crystal as quantization axis of the $J_{Z}$ component of the total angular momentum, the wave functions and energies in the absence of exchange field, but with crystalline field, are obtained by diagonalizing the Hamiltonian given by Hutchings [53] :

$$
\begin{aligned}
& \left.\begin{array}{r}
\left|\Gamma_{1}\right\rangle=0.6086|-3\rangle-0.5092|0\rangle- \\
-0.6086|+3\rangle
\end{array}\right\} \stackrel{009}{0} \\
& \left|\Gamma_{4}^{0}\right\rangle=0.7071|-3\rangle+0|0\rangle+ \\
& \begin{array}{r}
+0.7071|+3\rangle \\
\left|\Gamma_{4}^{-}\right\rangle=0.6238|-2\rangle-0.6235|+1\rangle- \\
-0.4713|+4\rangle
\end{array} \\
& \begin{array}{r}
\left|\Gamma_{4}^{+}\right\rangle=0.4713|-4\rangle+0.6235|-1\rangle+ \\
+0.6238|+2\rangle
\end{array}
\end{aligned}
$$

The exchange field $H_{\mathrm{m}}$, parallel to the $\langle 111\rangle$ direction, modifies the wave functions $\left|\Gamma_{1}\right\rangle$ and $\left|\Gamma_{4}^{0}\right\rangle$, because the matrix element $V=\left\langle\Gamma_{1}\left|g_{j} \mu_{\mathrm{B}} J_{Z}\right| \Gamma_{4}^{0}\right\rangle$ is non-zero. If one takes the experimental value $g_{j}=0.827$ for the $\mathrm{U}^{+4}$ free ion [54], one calculates $V=2.134 \mu_{\mathrm{B}}$.

The formalism used here has been detailed previously $[6,28,55]$.

(1) Application of the model to US. - Fixing a Curie temperature $(180 \mathrm{~K})$ and an ordered moment at $0 \mathrm{~K}\left(1.76 \mu_{\mathrm{B}}\right)$ close to the experimental ones we calculate the exchange constant $\lambda$ (163 c.g.s.), the molecular field at $0 \mathrm{~K}\left(1.6 \times 10^{6} \mathrm{Oe}\right)$, and the energy $\Delta E$ of the triplet $(320 \mathrm{~K})$. These values are slightly different from those calculated by Grunzweig-Genossar et al. [6].

In the ferromagnetic state, the distance in energy between the states of modified wave functions $\left|\Gamma_{1}^{\prime}\right\rangle$ and $\left|\Gamma_{4}^{\prime \prime}\right\rangle$ is $\sqrt{\Delta E^{2}+4 V^{2} H_{\mathrm{m}}^{2}}$, i.e. $555 \mathrm{~K}$. The Van Vleck susceptibility calculated in the ferromagnetic state at $0 \mathrm{~K}$ is $4.65 \times 10^{-3} \mathrm{cgs} / \mathrm{mole}$, of the same order of magnitude as the high field susceptibility measured by Gardner and Smith [34] $\left(3.78 \times 10^{-3} \mathrm{cgs} /\right.$ mole).

(2) Extension of the model to $\left(\mathrm{U}_{x} \mathrm{Th}_{1-x}\right) \mathrm{S}$. - We have calculated the dependence of the Curie temperature on the uranium concentration making the following hypothesis :

- The crystal field has the same value as for $\mathrm{US}(\Delta E=320 \mathrm{~K})$.

- The molecular field constant decreases proportionally to the uranium content.

It has been demonstrated that the magnetic order disappears when the $\lambda / \Delta E$ ratio becomes smaller than a critical value $(0.293$ if $\Delta E$ is in $\mathrm{K}$, and $\lambda$ in c.g.s. units).

The critical uranium concentration for threshold of ferromagnetism is calculated to be $x_{\mathrm{c}}=0.56$, the experimental value being $x_{\mathrm{c}}=0.43$.

The calculated Curie temperatures are :

$T_{\mathrm{c}}=137 \mathrm{~K}$ for $x=0.82$ (observed value : $117 \mathrm{~K}$ ).

\begin{tabular}{|c|c|c|c|c|}
\hline Sample & $\begin{array}{c}\text { Measured } \\
\text { Moment } \\
\text { (neutrons) }\end{array}$ & $\begin{array}{c}\text { Measured } \\
\text { Moment } \\
\text { (corrected } \\
\text { magnetization) }\end{array}$ & $\begin{array}{c}\text { Calculated } \\
\text { Moment } \\
\left(5 \mathrm{f}^{2} \text { model }\right)\end{array}$ & $\begin{array}{c}\text { Calculated } \\
\text { Moment } \\
\text { (J. W. model, } \\
p=7)\end{array}$ \\
\hline- & - & - & - & - \\
\hline US & 1.70 & 1.70 & 1.76 & 1.70 \\
\hline$x=0.82$ & $1.3 \pm 0.3$ & 1.16 & 1.50 & 1.38 \\
\hline$x=0.61$ & $0.9 \pm 0.3$ & 0.62 & 0.70 & 0.70 \\
\hline$x=0.563$ & - & $\begin{array}{c}0.50 \\
\text { (interpolated) }\end{array}$ & 0 & 0.53 \\
\hline$x=0.42$ & - & 0.07 & 0 & 0.13 \\
\hline$x=0.20$ & - & & 0 & 0.001 \\
\hline
\end{tabular}
$T_{\mathrm{c}}=76 \mathrm{~K}$ for $x=0.61$ (observed value : $55 \mathrm{~K}$ ).

TABLE V

Comparison of measured and calculated ordered magnetic moments in $\left(\mathrm{U}_{x} \mathrm{Th}_{1-x}\right) \mathrm{S}$ 
Their dependence with concentration is reported on figure 4 where it is compared with the experimental one.

We have also calculated for several values of $x$ the ordered moment $M$ per metal atom which is compared in table $\mathrm{V}$ and figure 4 with the values deduced from magnetization measurements (multiplied by a factor 1.097 to correct for band polarization, see $\S 6.2$ ) and with the values deduced from neutron scattering experiments.

7.2 ITINERANT 5f MODEL : CHEMICAL ENVIRONMENT AND INTERATOMIC EXCHANGE. - Because the $5 f$ bands are very narrow, crossing the Fermi level in US and situated at several $\mathrm{eV}$ above the Fermi level in $\mathrm{ThS}$, any rigid band model seems unlikely for $\left(\mathrm{U}_{x} \mathrm{Th}_{1-x}\right) \mathrm{S}$. It has been shown by C.P.A. theory and confirmed experimentally by photoemission measurements [56] that the $3 \mathrm{~d}$ density of states in $\mathrm{Ni}-\mathrm{Cu}$ alloys resembles a mixture of those of the two pure metals.

The most correct simple picture of the electronic structure of $\left(\mathrm{U}_{x} \mathrm{Th}_{1-x}\right) \mathrm{S}$ alloys consists then of interacting $5 \mathrm{f}$ virtual bound states on uranium atoms. Assuming a non-magnetic picture for dilute uranium in $\mathrm{ThS}$, as suggested in the beginning of $\S 7$, the occurrence of localized moments in $\left(\mathrm{U}_{x} \mathrm{Th}_{1-x}\right) \mathrm{S}$ should be extremely sensitive to the chemical and (/or) magnetic environment of each uranium atom.

It is now well known that the threshold of a localized magnetic moment on a transition metal atom diluted in a non-magnetic matrix alloy depends in a crucial way on the chemical nature of its environment [57, 58]. From a theoretical point of view, this local environment determines a local electronic density of states, i.e. the width and energy of the $3 \mathrm{~d}$ virtual bound state, and the possible occurrence of a localized magnetic moment [75].

Such chemical environment models have been later extended to the appearance of magnetic moments in concentrated alloys, especially vanadium in $\mathrm{Au}-\mathrm{V}$ alloys [59] and nickel in $\mathrm{Ni}-\mathrm{Cu}$ alloys [60]. But in these cases, one has to take into account interatomic exchange : the occurrence and value of a localized moment may depend both on its magnetic and chemical environment.

An extended review and discussion of such effects is given by Garland and Gonis [61], but the complete theory is not made yet, since it needs to go beyond the C.P.A. approximation.

Assuming an itinerant $5 f$ model for $\left(\mathrm{U}_{x} \mathrm{Th}_{1-x}\right) \mathrm{S}$ alloys, we do not know the relative importance of chemical and magnetic environment for the occurrence of localized moments. Tentatively, we have analyzed the magnetization values of $\S 5$ in a very simple Jaccarino-Walker model [57]. We assume that the uranium moment has a value of 1.7 or $0 \mu_{\mathrm{B}}$, depending only on its first shell chemical environment. As the alloys with small uranium concentration seem to contain only very few localized moments, the sug- gested criterion for the appearance of such a moment is that it has at least $p$ uranium first neighbours. For a $\left(\mathrm{U}_{x} \mathrm{Th}_{1-x}\right) \mathrm{S}$ alloy, the relative number of uranium atoms having a moment is then :

$$
F(x)=\sum_{i=p}^{12} \frac{12 !}{i !(12-i) !} x^{i}(1-x)^{12-i}
$$

and the average magnetic moment per metal atom is $1.7 x F(x) \mu_{\mathrm{B}}$. This function is plotted in figure 4 and table III for the case $p=7$ which gives the best agreement with the data.

7.3 COMPARISON OF THE $5 \mathrm{f}^{2}$ AND THE CHEMICAL Jaccarino-Walker (J. W.) MODELS. - As shown in figure 4 and table $\mathrm{V}$, the two models predict disappearance of ferromagnetism at a rather high uranium concentration, and this is in good agreement with the experimental observations. For the $5 \mathrm{f}^{2}$ model, we have calculated the critical composition as $x_{\mathrm{c}}=0.56$. In the chemical J. W. model, the number of localized moments at the experimental critical concentration $x_{\mathrm{c}} \simeq 0.43$ is about $9 \%$ of the total number of metallic atoms : $9 \%$ is the order of magnitude of the critical concentration in a FCC lattice for the appearance of long-range ferromagnetic order, if one assumes ferromagnetic interactions between first neighbours only [51].

Both models predict finally a non-linear concentration dependence of magnetization and Curie temperature ; in particular, the $5 \mathrm{f}^{2}$ model predicts a catastrophic decrease of these two quantities around the critical composition. This is not experimentally observed, at least for Curie temperature and in consequence, the chemical Jaccarino-Walker model, which shows a smoother transition, is in better agreement with our results. However, the $\mathbf{J}$. W. model is very crude, so the $p=7$ value should not be taken too seriously. On the other hand, the $5 \mathrm{f}^{2}$ model presented here, which treats the alloy as homogeneous, could be refined, attributing to each uranium atom a crystal field and an exchange field depending on its environment. But, in the absence of more experimental information, the better fit obtained from this refinement would be rather illusory because of the greater number of variable parameters.

8. Low temperature $(1.5<\boldsymbol{T}<10 \mathrm{~K})$ specific heat measurements. - 8.1 EXPERIMENTAL RESULTS. These measurements have been made on ThS and the four solid solutions $\left(\mathrm{U}_{0.25} \mathrm{Th}_{0.75}\right) \mathrm{S},\left(\mathrm{U}_{0.44} \mathrm{Th}_{0.56}\right) \mathrm{S}$, $\left(\mathrm{U}_{0.61} \mathrm{Th}_{0.39}\right) \mathrm{S},\left(\mathrm{U}_{0.82} \mathrm{Th}_{0.18}\right) \mathrm{S}$. (The last two samples had been studied also by magnetization and neutron scattering). They are represented on figure 5 in the analytical form $C_{\mathrm{p}} / T=\alpha T^{2}+\gamma$, justified by the fact that the hyperfine specific heat is negligible for $U$, Th and $S$ in natural isotopic concentration. The specific heat of US, measured by Westrum et al. [7] is also represented on this figure. The variation $C_{\mathrm{p}} / T=f\left(T^{2}\right)$ is linear to the precision of experiments 


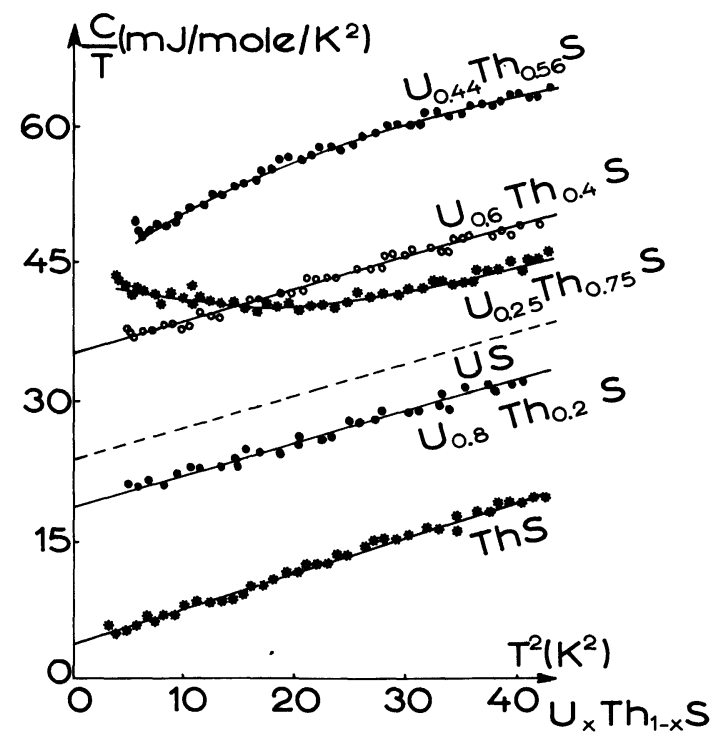

FIG. 5. - Specific heat of the mixed sulphides $\left(\mathrm{U}_{x} \mathrm{Th}_{1-x}\right) \mathrm{S}$ between 1.5 and $10 \mathrm{~K}$.

for ThS and for the two compounds $x=0.82$ and $x=0.61$, but not for the two other compositions.

We give in the table VI the following values, estimated for the 4 compounds US [7], $x=0.82, x=0.61$, ThS :

- $\gamma$ and $\alpha$; the values of $\gamma$ have been corrected to take into account the $\simeq 1 \%$ ThOS electrical insulator, present in our samples.

- The apparent density of states per spin direction at the Fermi level : $N\left(E_{\mathrm{f}}\right)$ calculated from $\gamma$ in the Sommerfeld model (ref. [21], p. 178).

- The apparent Debye temperature of the acoustical modes of phonon, associated to three degrees of freedom for the $\left(\mathrm{U}_{x} \mathrm{Th}_{1-x}\right) \mathrm{S}$ molecule (calculated from $\alpha$ ).

- The measured Einstein temperature determined by inelastic neutron scattering (see $\S 10$ ).

For the two compounds of uranium content $x=0.25$ and 0.44 , the variation $C_{\mathrm{p}} / T=f\left(T^{2}\right)$ is non linear, but approximative values $\gamma \simeq 30 \mathrm{~mJ} /$ mole $/ \mathrm{K}^{2}$ and $\simeq 40 \mathrm{~mJ} / \mathrm{mole} / \mathrm{K}^{2}$ can be respectively estimated from the curves of figure 5 (see $\S 8.2$ and 8.3).

The $\gamma$ coefficient (apparent electronic specific heat) is maximum around the critical composition $x_{\mathrm{c}} \simeq 0.43$ for the appearance of low temperature ferromagnetism.

The spin wave term has been separated by Westrum et al. [7] in US, and the Debye temperature of this compound correctly determined; we have then tried to check if US and ThS followed the Lindemann criterion (ref. [21], p. 13), to estimate then the real Debye temperature of the intermediate compounds. This criterion is written as $M V^{2 / 3} \theta_{\mathrm{D}}^{2} / T_{\mathrm{f}}=K$, where $K$ is a constant, $M$ is the molecular weight, $V$ the atomic volume, $\theta_{\mathrm{D}}$ the Debye temperature, $T_{\mathrm{f}}$ the melting temperature (given in the ref. [10]). The values of $K$ obtained are slightly different for ThS and US (3.86 and 4.27 in arbitrary units), and we have assumed that it varies linearly with uranium content $x$; from the atomic volume and melting temperatures [10] of the mixed compounds $\left(\mathrm{U}_{x} \mathrm{Th}_{1-x}\right) \mathrm{S}$ we have deduced the values of $\theta_{\mathrm{D}}$ for our four compositions.

Calculated and apparent values of $\theta_{\mathrm{D}}$ are compared on table VI :

- For $x=0.82$, the fit is good and the spin wave term seems thus quite small.

- For $x=0.61$, the calculated value $(180.6 \mathrm{~K})$ is smaller than the apparent one $(189.7 \mathrm{~K})$ : the calculated $\alpha$ coefficient is then bigger than the experimental one, and this can only be explained by a thermal variation of $\gamma: \gamma=36.4-0.045 T^{2}\left(\mathrm{~mJ} / \mathrm{mole} / \mathrm{K}^{2}\right)$.

8.2 SPECIFIC HEAT OF $\left(\mathrm{U}_{0.44} \mathrm{Th}_{0.56}\right) \mathrm{S}$. - For this composition, the extrapolation of the Curie temperature curve versus concentration (Fig. 4) shows ferromagnetism at $0 \mathrm{~K}$ and a Curie temperature of about $5 \mathrm{~K}$.

In fact, $C / T$ versus $T^{2}$ plot of the specific heat of this sample shows a negative curvature. If one draws

\section{TABLE VI}

Low temperature specific heat data and Einstein temperatures measured by neutron inelastic scattering in $\left(\mathrm{U}_{x} \mathrm{Th}_{1-x}\right) \mathrm{S}$

\begin{tabular}{|c|c|c|c|c|c|c|}
\hline & $\underline{\mathrm{ThS}}$ & $x=0.25$ & $x=0.44$ & $x=0.61$ & $x=0.82$ & US [7] \\
\hline$\gamma\left(\mathrm{mJ} / \mathrm{mole} / \mathrm{K}^{2}\right)$ & $\begin{array}{ll}3.7 & {[20]} \\
3.9 & \end{array}$ & 33.2 & $42 \pm 2$ & $36.4^{\prime}$ & 19.45 & 23.4 \\
\hline$\alpha\left(\mu \mathrm{J} / \mathrm{mole} / \mathrm{K}^{4}\right)$ & $\begin{array}{ll}398 & {[20]} \\
383\end{array}$ & 245 & & 285 & 309 & 283 \\
\hline $\begin{array}{l}N\left(E_{\mathrm{f}}\right) \text { states } / \mathrm{eV} / \text { metal } \\
\quad \text { atom } / \text { spin }\end{array}$ & $\begin{array}{l}0.78[20] \\
0.83\end{array}$ & 7.04 & 8.9 & 7.72 & 4.12 & 4.96 \\
\hline$\theta_{\mathrm{D}}$ apparent $(\mathrm{K})$ & $\begin{array}{l}169.8 \\
172.2\end{array}$ & 202 & & 189.7 & 184.9 & 190 \\
\hline$\theta_{\mathrm{D}}$ calculated $(\mathrm{K})$ & 172.2 & 174.7 & 177.7 & 180.6 & 185 & 190 \\
\hline$\theta_{\mathrm{E}}(\mathrm{K})$ & $363 \pm 20$ & & & $460 \pm 30$ & $430 \pm 20$ & $410 \pm 15$ \\
\hline
\end{tabular}


on this plot a straight line $C / T=\beta T^{2}$ corresponding to the lattice specific heat (calculated from $\theta_{\mathrm{D}}$ cal $=177.7 \mathrm{~K}$, see table $\mathrm{VI}$ ), one can see that the difference between the measured $C / T$ curve and the straight line $\beta T^{2}$ is maximum for $T \simeq 4.5 \mathrm{~K}$, a temperature close to the calculated Curie temperature. The negative curvature of $C / T=f\left(T^{2}\right)$ is perhaps then explained by a broad ferro-paramagnetic transition.

It is difficult to determine $\gamma$. We quote the value $\gamma=42 \pm 2 \mathrm{~mJ} / \mathrm{mole} / \mathrm{K}^{2}$, extrapolated from the $C / T$ curve between 2 and $3 \mathrm{~K}$.

8.3 SPECIFIC HEAT OF $\left(\mathrm{U}_{0.25} \mathrm{Th}_{0.75}\right) \mathrm{S}$. The samples of uranium content $0.20<x<0.43$ are not ferromagnetic at low temperature : but because of their strong magnetic susceptibility at $4 \mathrm{~K}$ [15], they can be characterized as nearly ferromagnetic. The curvature of $C / T=f\left(T^{2}\right)$ observed for $x=0.25$ (see Fig. 5) has been often encountered in nearly ferromagnetic metallic solid solutions : $\mathrm{Ni}-\mathrm{Cu}$ [62], Fe-V [64], Ni-Rh [65] but not in Pd-Ni [63].

Two models have been invoked to explain this behaviour :

- Spin fluctuations or paramagnons in a narrow band with strong exchange interactions [66]. These fluctuations lead to a logarithmic term in the low temperature specific heat, i.e. to a positive curvature of $C / T$ against $f\left(T^{2}\right)$. But, from a numerical point of view, the measured specific heat of $\left(\mathrm{U}_{0.25} \mathrm{Th}_{0.75}\right) \mathrm{S}$ does not fit well the theoretical formula of ref. [66]. This is not surprising since this logarithmic term is strongly reduced in the case of alloys [67], and thus has not been encountered in Pd-Ni alloys [63] where the paramagnon theory should apply best.

- Superparamagnetic clusters fluctuating against anisotropy $[65,68]$. This leads generally to a constant Einstein specific heat in a range of temperature around $4 \mathrm{~K}$ [69]. We have analyzed the specific heat of $\left(\mathrm{U}_{0.25} \mathrm{Th}_{0.75}\right) \mathrm{S}$ under the analytical form :

$$
C=A+\gamma T+\alpha T^{3},
$$

and the least squares technique gives with a good fit : $C\left(\mathrm{~mJ} / \mathrm{mole} / \mathrm{K}^{2}\right)=$

$$
=11.76+33.2 T+0.366 T^{3}-0.121 T^{3},
$$

where the term $0.366 T^{3}$ is the lattice term obtained from the Debye temperature calculated in table VI (174.7 K).

The constant term $A$ allows us to calculate the number of clusters per mole :

$$
N_{\mathrm{a}} \simeq 8.5 \times 10^{20} \text {. }
$$

In the absence of more extensive information, it is difficult to say if these magnetic clusters which probably contributed largely to magnetic susceptibility below $180 \mathrm{~K}$ [15] are due to microsegregation or imperfect diffusion. One must remember that such clusters can arise in a completely random solid solution, because of statistical fluctuations of concentration, and polarization effects [61].

In conclusion, the existence of magnetic clusters seems to explain the increase of $C / T$ at low temperature in $\left(\mathrm{U}_{0.25} \mathrm{Th}_{0.75}\right) \mathrm{S}$, but not the large $\gamma$ value (cf. $\S 8.4$ ).

8.4 INTERPRETATION OF THE MAXIMUM OF $\gamma$ AT THE CRITICAL COMPOSITION $x_{\mathrm{c}} \simeq 0.43$. - As in the case of the solid solution $\mathrm{U}\left(\mathrm{C}_{1-x} \mathrm{~N}_{x}\right)$ [19], three possible explanations may be given :

- Maximum of the density of states at the Fermi level. Substituting $U$ to Th atoms in ThS, one introduces $5 f$ virtual bound states which increase $\gamma$. If the uranium content is sufficiently large $(>5 \%)$, one must rather speak of a hybrid $5 \mathrm{f}-6 \mathrm{~d}$ band. The exchange field which appears for $x>0.43$ partially splits the spin-up and spin-down bands on both sides of the Fermi level, hence the decrease of density of states.

- Coupling between the $5 \mathrm{f}-6 \mathrm{~d}$ band electrons and paramagnons, leading to an increase of the electronic effective mass at the Fermi level, as we have seen $\S 8.3$. These paramagnon effects are maximum at the critical concentration for ferromagnetism threshold.

- Existence of a purely magnetic $\gamma T$ contribution to the specific heat, if a significant number of uranium sites see a symmetrical (positive, negative, and null) and continuous distribution of small molecular fields. But this has been justified only in the case of an Ising model [70, 71]. The specific heat of superparamagnetic clusters (cf. $\S 8$ 8-3) also contributes to $\gamma$ [69] but we have calculated this contribution as being a factor 10 smaller than the measured $\gamma$.

9. Specific heat measurements between 10 and $300 \mathrm{~K}$. - These measurements, made on ThS, $\left(\mathrm{U}_{0.61} \mathrm{Th}_{0.39}\right) \mathrm{S}$, and $\left(\mathrm{U}_{0.82} \mathrm{Th}_{0.18}\right) \mathrm{S}$ are shown in figure 6 and table VI.

9.1 ThORIUM MONOSUlPHIDE ThS. - Our specific heat values of $\mathrm{ThS}$ are greater by about $1 \%$ than those of Flotow et al. [20].

We have estimated the lattice specific heat of ThS, by subtracting two contributions to the measured $C_{\mathrm{p}}$ :

- An electronic specific heat $\gamma T$, proportional to absolute temperature, being determined between 1.5 and $7 \mathrm{~K}$ (table VI).

- A thermal expansion specific heat term $\left(\mathrm{C}_{\mathrm{p}}-C_{\mathrm{v}}\right)_{\mathrm{d}}$, obtained from published information on the order of magnitude of the thermal lattice expansion and elastic constants of uranium and thorium based ceramics [40]. These evaluations do not need a great precision because, at $300 \mathrm{~K},\left(C_{\mathrm{p}}-C_{\mathrm{v}}\right)_{\mathrm{d}} \simeq 0.01 C_{\mathrm{p}}$.

We have then compared the lattice specific heat obtained $C_{\mathrm{R}}(T)$ to the sum of a Debye term (acoustic phonons, $\theta_{\mathrm{D}}=172 \mathrm{~K}$ ) and of an Einstein term (optical phonons $\theta_{\mathrm{E}}=394 \mathrm{~K}$, being a single Einstein temperature because $\mathrm{ThS}$ is metallic). The agreement 

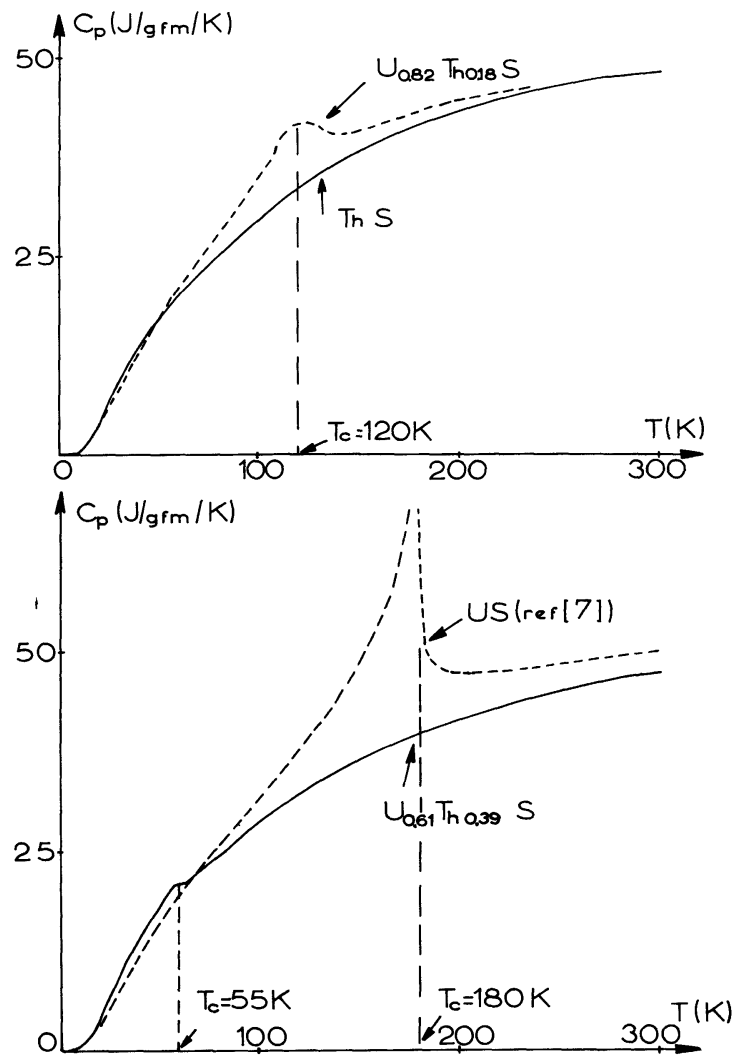

Fig. 6. - Specific heat of $\left(\mathrm{U}_{x} \mathrm{Th}_{1-x}\right) \mathrm{S}$ between 1.5 and $300 \mathrm{~K}$.

is very good except between 15 and $120 \mathrm{~K}$, the temperature range where the Debye approximation cannot correctly describe the acoustic vibration specific heat of the crystal lattice. Note that the Einstein temperature used here is slightly greater than the neutron scattering result.

\subsection{MiXed SUlPHIDES}

$$
\left(\mathrm{U}_{0.82} \mathrm{Th}_{0.18}\right) \mathrm{S}, \quad\left(\mathrm{U}_{0.61} \mathrm{Th}_{0.39}\right) \mathrm{S} .
$$

- The curves of figure 6 show clearly maxima at the Curie temperatures : $T_{\mathrm{C}}=117 \mathrm{~K}$ for $x=0.82$, $T_{\mathrm{C}}=55 \mathrm{~K}$ for $x=0.61$.

We have tried to estimate the lattice specific heat of these two compounds and of US from the one of ThS :

- assuming that the optical modes contribute to the specific heat by an Einstein term, the Einstein temperatures being given by the results of $\S 10$ (table VI);

- applying only to the specific heat $C_{\mathrm{ac}}$ of the acoustical modes the so-called corresponding states empirical law [72],

$$
C_{\mathrm{ac}}^{(\mathrm{U}, \mathrm{Th}) \mathrm{S}}(T)=C_{\mathrm{ac}}^{\mathrm{Ths}}\left(T \frac{\theta_{\mathrm{D}}(\mathrm{U}, \mathrm{Th}) \mathrm{S}}{\theta_{\mathrm{D}} \mathrm{ThS}}\right)
$$

which assumes that the dispersion curves of the US acoustical modes are similar to those of ThS. This law (which does not take into account the rhombohedral distortion in the ferromagnetic state of US) is applicable only if the valence of $U$ in US is near 4 and if the $5 \mathrm{f}$ states do not participate to the bonding.

The difference between the measured specific heat and the calculated lattice one (to which we have added a $\left(C_{\mathrm{p}}-C_{\mathrm{v}}\right)_{\mathrm{d}}$ contribution calculated as for $\left.\mathrm{ThS}\right)$ is then the sum of the electronic and magnetic specific heat of the $\left(\mathrm{U}_{x} \mathrm{Th}_{1-x}\right) \mathrm{S}$ compounds.

The three functions $C_{\mathrm{el}}+C_{\text {magn }}$ (for $x=0.61$, $0.82,1.00)$ are represented on figure 7 .
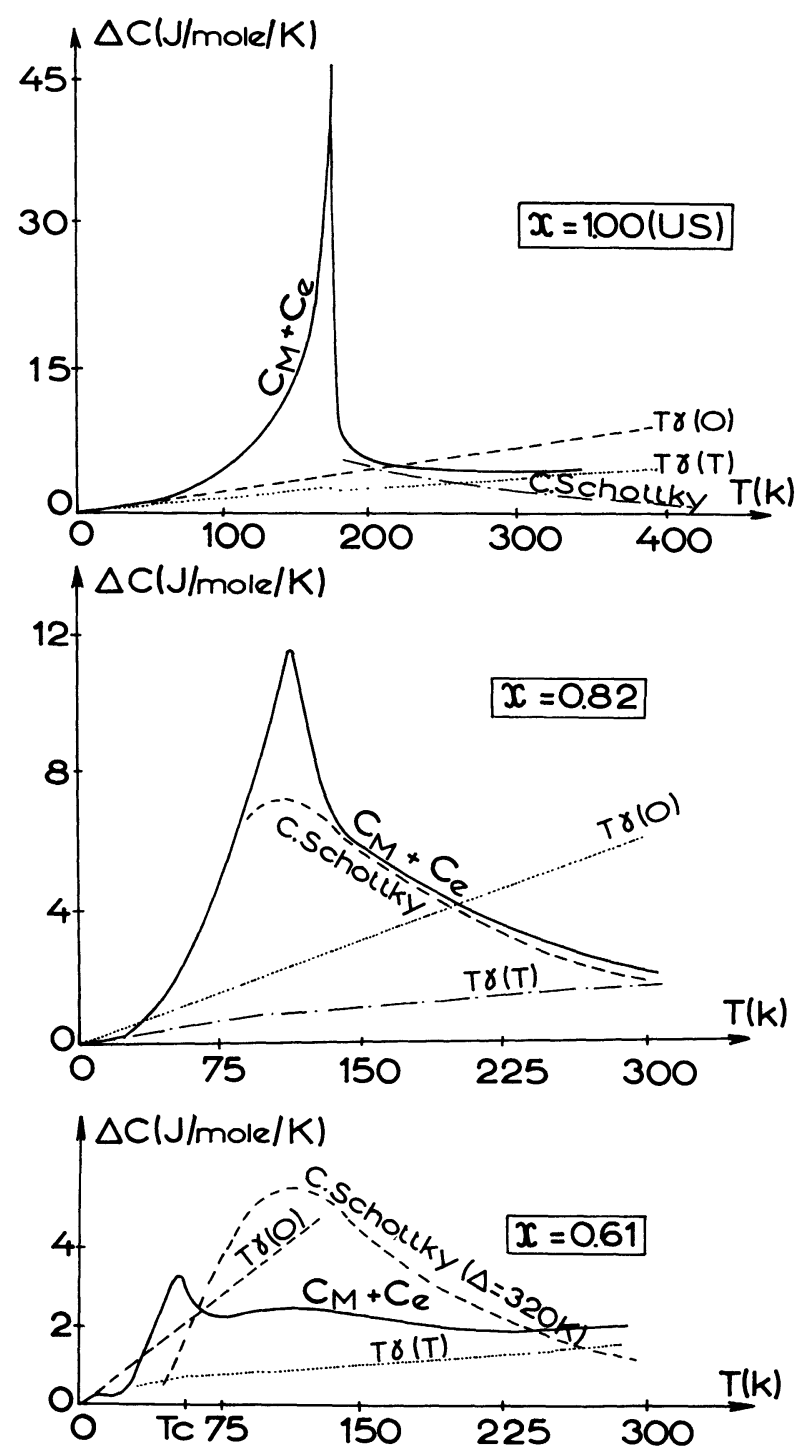

FIG. 7. - Magnetic plus electronic specific heat $C_{\mathrm{M}}+C_{\mathrm{E}}$ of $\left(\mathrm{U}_{x} \mathrm{Th}_{1-x}\right) \mathrm{S}$ compared to the theoretical C. Schottky specific heat of the localised $5 \mathrm{f}^{2}$ model. Are also given on the figure the electronic specific heat $T \gamma(0)$ extrapolated from low temperature and the estimated $T \gamma(T)$ electronic specific heat.

Two main comments can be made about these curves :

- One apparently does not observe in the paramagnetic state $\left(T>T_{\mathrm{c}}\right)$ the Schottky anomalies predicted by the localized $5 \mathrm{f}^{2}$ model : the dotted curve calculated with $\Delta E=320 \mathrm{~K}$ shows a maximum at 
about $110 \mathrm{~K}$, but this does not appear on the experimental curve for $x=0.61$.

- The $\gamma$ coefficients of electronic specific heat decrease quite rapidly with increasing temperature. At $300 \mathrm{~K}$, these values are less than or equal to $15 \mathrm{~mJ} / \mathrm{mole} / \mathrm{K}^{2}$ (US), and $7 \mathrm{~mJ} / \mathrm{mole} / \mathrm{K}^{2}(x=0.82$ and 0.61 ) (the equality is obtained if the magnetic specific heat $C_{\mathrm{M}}$ is assumed to be zero at $300 \mathrm{~K}$ ).

It seems then very difficult from a practical point of view to separate the magnetic and electronic specific heats, the two terms being of the same order of magnitude and depending on temperature in a complicated way. (It is even more difficult if the $\gamma$ coefficient at low temperature contains a magnetic contribution for $x=0.61$.) This separation is also questionable from a theoretical point of view, both contributions being due to the $5 \mathrm{f}$ band : one has then to distinguish individual electronic excitations $(\gamma(T) T)$ and collective ones $\left(C_{\mathrm{M}}(T)\right)$; this can be made satisfactorily at low temperature in the case of transition metals [73], but is more difficult at higher temperature.

The magnetic susceptibility of US follows exactly a Curie-Weiss law above $225 \mathrm{~K}$, and one can suppose that the short-range magnetic order is then small. This allows a first estimation of the magnetic entropy of our three samples, assuming the magnetic specific heat is zero at $300 \mathrm{~K}$, and that $\gamma(T)$ decreases monotonically (in a somewhat arbitrary way, see figure 7) from its low temperature value (table VI) to its maximum possible value at $300 \mathrm{~K}$ estimated above.

The magnetic entropies estimated at $350 \mathrm{~K}$ are then :

US : $\Delta S_{\mathrm{m}} \simeq 7.9 \mathrm{~J} /$ mole (instead of 8.8 estimated by Flotow et al. [20] with slightly different approximations).

$\left(\mathrm{U}_{0.82} \mathrm{Th}_{0.18}\right) \mathrm{S}: \Delta S_{\mathrm{m}} \simeq 7.2 \mathrm{~J} / \mathrm{mole}$.

$\left(\mathrm{U}_{0.61} \mathrm{Th}_{0.39}\right) \mathrm{S}: \Delta S_{\mathrm{m}} \simeq 3.8 \mathrm{~J} / \mathrm{mole}$ if the low temperature $\gamma T$ term does not contribute at all to the magnetic specific heat, and $\Delta S_{\mathrm{m}} \simeq 4.8 \mathrm{~J} / \mathrm{mole}$ if about $20 \mathrm{~mJ} / \mathrm{mole} / \mathrm{K}^{2}$ of the $\gamma$ coefficient is of magnetic origin.

Assuming a smaller $\gamma$ value at $300 \mathrm{~K}$ leads to a somewhat larger magnetic entropy $\Delta S_{\mathrm{m}}$ : typically for US, $\gamma(300 \mathrm{~K})=7 \mathrm{~mJ} / \mathrm{mole} / \mathrm{K}^{2}$ instead of 15 leads to $\Delta S_{\mathrm{m}} \simeq 9.1 \mathrm{~J} /$ mole instead of 7.9 .

10. Neutron inelastic scattering results. - The technique for determining the energy of the optical phonons in UX compounds is described by Wedgwood [43]. In the case of the sulphides this optical peak in the time-of-flight spectrum is weak due to the low scattering length of sulphur : $0.28 \times 10^{-12} \mathrm{~cm}$ compared to $0.95 \times 10^{-12}$ for nitrogen for example. Furthermore in the case of the sulphides rich in uranium there is an additional scattering mechanism due to the magnetic moment. It is thus necessary to make a separation of the two forms of scattering to get an accurate optical phonon energy. This is possible since the one phonon scattering is proportional to the square of the momentum change $Q$, whereas the magnetic scattering is proportional to the square of the magnetic form factor $f(Q)$, a decreasing function of $Q$. The time-of-flight data, which is determined at 30 values of $Q$ for each value of time-of-flight (and therefore energy transfer) is fitted to the function

$$
\sigma(t)=P(t) Q^{2} \mathrm{e}^{-W(Q)}+M(t) f^{2}(Q)
$$

where $P(t)$ and $M(t)$ are now the lattice and magnetic spectra and $\mathrm{e}^{-W(Q)}$ is the Debye-Waller factor. $f(Q)$ and $W(Q)$ are taken from the data on pure US [5].

The two spectra are shown for pure US in figure 8 . Similar $P(t)$ spectra were observed for the mixed sulphides with $x=0.82,0.61$ and 0.44 and the estimated optical frequencies are reported in table VI in terms of the Einstein temperatures $\theta_{\mathbf{E}}$. There is a tendency, which may not be significant due to the large statistical errors, for the mixed compounds to have higher Einstein temperatures than for the pure compounds.

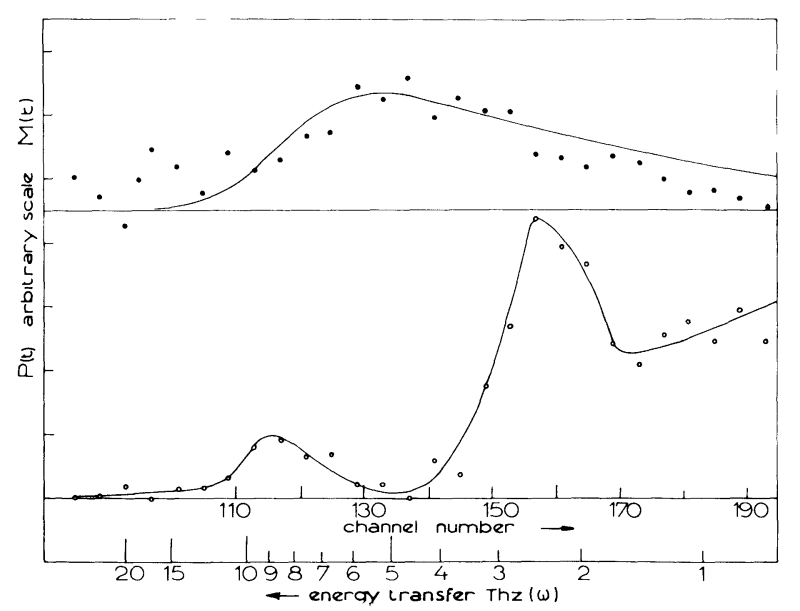

FíG. 8. - Lattice and magnetic contributıons to the inelastic neutron scattering time-of-flight spectrum. The fit to the magnetic spectrum is the gaussian $\exp \left(-E^{2} / 2 E_{0}^{2}\right)$ where $E_{0}=17 \mathrm{meV}$.

The function $M(t)$ was only found to be significant for pure US; for the mixed compounds where the magnetic scattering is less and smaller samples were used, statistical fluctuations are too large. For pure US it can be seen that the data is not strongly peaked as might be expected for a localized model with crystal field transitions. We have interpreted the data using the De Gennes formula for scattering from a paramagnet with exchange coupling [74] :

$$
\begin{gathered}
\frac{\partial^{2} \sigma}{\partial \Omega \partial \omega} \propto \frac{k^{\prime}}{k} f^{2}(Q)\left(2 \pi\left\langle\omega^{2}\right\rangle\right)^{-1 / 2} \exp \left(-\frac{\omega^{2}}{2\left\langle\omega^{2}\right\rangle}\right) \\
\left\langle\omega^{2}\right\rangle=\frac{8}{3} S(S+1) \sum_{r} J^{2}(r)
\end{gathered}
$$

Here $h^{2}\left\langle\omega^{2}\right\rangle$ is the second moment of the transferred energy, $k$ and $k^{\prime}$ are the initial and final neutron 
momenta and $J(r)$ is the exchange energy between magnetic atoms at 0 and $r$. On the time-of-flight scale this becomes distorted to :

$$
M(t) \propto \frac{1}{t^{4}} \exp \left(-\frac{\omega^{2}}{2\left\langle\omega^{2}\right\rangle}\right)
$$

and the smooth line in figure 8 is a least squares fit to $M(t)$ giving $\left\langle\omega^{2}\right\rangle^{1 / 2} \simeq 200 \mathrm{~K}$. Since we have no clear value to give for $S$ no further conclusion can be made but it is obviously of the right order of magnitude since :

$$
\theta_{\mathrm{p}}=180 \mathrm{~K}=\frac{2}{3} S(S+1) \sum_{r} J(r) .
$$

On the localized $5 \mathrm{f}^{2}$ model one would expect a $\Gamma_{4}-\Gamma_{1}$ transition at about $320 \mathrm{~K}(6.7 \mathrm{THz})$. This would of course be broadened by the exchange field in the same way as the zero energy peak but even so there is not much sign of it. Unfortunately at these energies the momentum change $Q$ is quite large and $f^{2}(Q)$ correspondingly small; so it is possible that crystal field peaks could go undetected if they are above about $10 \mathrm{THz}$. Nevertheless this data on pure US seems to give further evidence that the simple localized model is incorrect.

11. Discussion. - $\left(\mathrm{U}_{\boldsymbol{x}} \mathrm{Th}_{1-x}\right) \mathrm{S}$ alloys are now known to be at low temperature ferromagnetic for $x=\frac{\mathrm{U}}{\mathrm{U}+\mathrm{Th}}>0.43$ and paramagnetic for $x<0.43$.

The physical understanding of our results is enlightened by the recently performed [44] electrical resistivity and magnetic susceptibility measurements on samples with low uranium content $(0.01<x<0.15)$ : the thermal variation of magnetic susceptibility, $\chi=\chi_{0}+C /\left(T+\theta_{\mathrm{p}}\right)$ with $\theta_{\mathrm{p}} \simeq 150 \mathrm{~K}$, discards the simple $5 \mathrm{f}^{1}, 5 \mathrm{f}^{3}, 5 \mathrm{f}^{4}$ configurations which all predict pure Curie susceptibility $\chi=C / T$ in the dilute uranium limit. On the contrary, the results presented in the present paper, as well as those performed on low uranium content samples suggest a non magnetic ground state for uranium dissolved in ThS. This could be due to the combined crystal field and spin-orbit coupling acting on a localized $5 \mathrm{f}^{2}$ configuration, or to a sufficient hybridization of $5 f$ levels with the s-p-d conduction bands.

Sufficient interaction between uranium atoms results then in the threshold of localized moments : this may be due to chemical environment effects (modifying the density of states of $5 f$ virtual levels) and/or to interatomic exchange which exists in both the localized and itinerant $5 \mathrm{f}$ models.

1) Our experiments have allowed us to analyze in detail the $5 \mathrm{f}^{2}$ model, and showed that it is not very likely :
- it predicts a catastrophic decrease of magnetization around the critical composition, and this is not observed : there must be at least a strongly inhomogeneous magnetization around $x_{\mathrm{c}}=0.43$,

- specific heat measurements on $\left(\mathrm{U}_{0.61} \mathrm{Th}_{0.39}\right) \mathrm{S}$ and inelastic neutron scattering on US failed to reveal the existence of an excited crystal field level around $300 \mathrm{~K}$,

- it predicts an increase with temperature of the magnetic contribution to electrical resistivity, when the observed resistivity decreases with increasing temperature for $x<0.43$ (see Fig. 9 and ref. [44]).

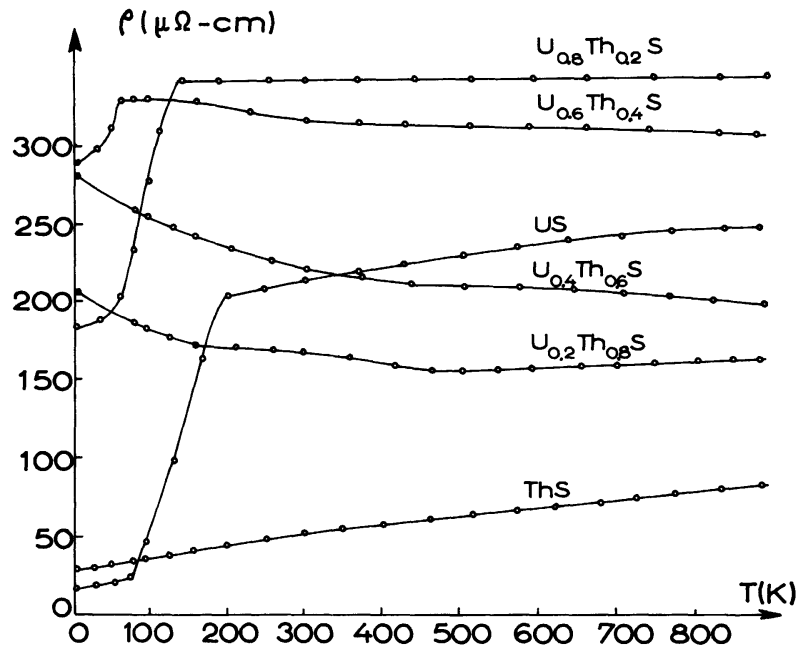

IIG. 9. - Electrical resistivity of $\left(\mathrm{U}_{x} \mathrm{Th}_{1-x}\right) \mathrm{S}$ (from ref. [14]).

2) We want now to discuss the possibility of interconfiguration fluctuations (ICF) such as those proposed by Hirst [78] and Sales and Wohlleben [79] for rare earth compounds. This model was used to analyze the XPS spectra of the thulium compounds TmSe and TmTe, where the lines corresponding to the $4 \mathrm{f}^{12}$ and $4 \mathrm{f}^{13}$ configurations are found side by side [80]. On the contrary, in TmSe, inelastic neutron scattering did not reveal the excited crystal-field levels [81], probably because the ICF are faster than the characteristic inverse frequency of a thermal neutron (but not of an X-ray photon); this could explain the absence of crystal-field levels in the neutron measurements on US. In principle, the ICF model could apply to uranium, because the difference in energy between the $5 f^{2}(6 d 7 s)^{4}, 5 f^{3}(6 d 7 s)^{3}$ and $5 f^{1}(6 d 7 s)^{5}$ configurations is only of the order of $1 \mathrm{eV}$ in the free atom [82] and may be reduced in the compounds; in US or $\left(\mathrm{U}_{x} \mathrm{Th}_{1-x}\right) \mathrm{S}$, the ICF should be between $5 \mathrm{f}^{2}$ and $5 \mathrm{f}^{3}$ or $5 \mathrm{f}^{2}$ and $5 \mathrm{f}^{1}$ : the fundamental state is $5 \mathrm{f}^{2}$ (see $\left.\$ 2.2\right)$ rather than $5 \mathrm{f}^{3}$ as in the free atom, because the gain in binding energy is larger than the energy cost of the promotion $5 \mathrm{f} \rightarrow 6 \mathrm{~d}$.

Nevertheless, if an interconfiguration model qualitatively explains certain physical properties of US and $\left(\mathrm{U}_{x} \mathrm{Th}_{1-x}\right) \mathrm{S}$ such as the finite magnetic suscepti- 
bility at $T=0 \mathrm{~K}$ for $x<0.43$, we have some doubts upon its effective applicability to these compounds.

First, the main interest of the ICF description (versus the virtual bound state description) of the resonance between localized $5 f$ configurations and the conduction band is its capability of taking into account the detailed structure of the $\mathrm{f}^{n}$ configurations; this of course occurs only if the broadening of the levels by the $(\mathrm{s}, \mathrm{p}, \mathrm{d})-\mathrm{f}$ interactions is smaller than the multiplet or crystal-field splittings and is probably not the case in uranium sulphides : the $6 \mathrm{~d}-5 \mathrm{f}$ or $3 \mathrm{p}-5 \mathrm{f}$ matrix elements of the crystal potential between atomic orbitals on neighbouring sites are much larger $(\sim 0.1$ to $0.5 \mathrm{eV}$ [28]) than in rare earth compounds, suggesting that the $5 \mathrm{f}$ sharp levels loose their individuality.

Second, ICF models predict often an anomalous thermal expansion due to the change with temperature of the population between the two considered configurations; this is not observed in uranium compounds such as US [29]. On the other hand, ICF models do not explain the residual resistivity and electronic specific heat maxima at the critical composition for ferromagnetism $x_{\mathrm{c}}=0.43$.

Third, one should insist upon the fact that the observed magnetic susceptibility of mixed-valence rare earth compounds has been justified by the ICF model in a phenomenological way only [79], and that the quantitative demonstration of this behaviour is given starting from the Friedel-Anderson virtual bound state (VBS) model [83]. The relative validity of ICF and VBS models has been recently discussed by Hirst [84] and by Coqblin et al. [85].

3) In conclusion, we think that a virtual bound state approach in the Friedel-Anderson sense, or a narrow band model (Hubbard) is more appropriate for uranium compounds such as $\left(\mathrm{U}_{x} \mathrm{Th}_{1-x}\right) \mathrm{S}$. A similar conclusion has been reached recently for the compound $\mathrm{CeAl}_{3}$ [86].

In the dilute uranium $\left(\mathrm{U}_{x} \mathrm{Th}_{1-x}\right) \mathrm{S}$ alloys, the concentration and thermal variations of electrical resistivity is well described by non-magnetic 6-fold $(5 f, j=5 / 2)$ virtual bound states occupied by two electrons in order to satisfy the Friedel sum rule. The spin fluctuation temperature is about $150 \mathrm{~K}$ [44].

For rich uranium content alloys, a narrow $5 \mathrm{f}$ band description in a CPA model with strong hybridization to the $6 \mathrm{~d}$ bands should be preferred. One may then understand the ultraviolet photoemission measurements on US [9] and the strong value of the electronic specific heat $\gamma T$, maximum around $x_{\mathrm{c}}=0.43$; the appearance of ferromagnetism is explained by the Stoner criterion.

But, in order to explain the smoothness of the magnetic-non magnetic transition with concentration, local effects should be included. A very simple chemical environment model, neglecting interatomic exchange, and assuming that a constant magnetic moment (1.5-1.7 $\mu_{\mathrm{B}}$ ) exists on the only uranium atoms having at least 7 uranium first neighbours, fits roughly the concentration dependence of the magnetization.

According to the above discussion, the high residual resistivity of the non-ferromagnetic samples $(\sim 8 \mu \Omega$-cm/uranium percent in the dilute uranium limit [44]) is due to the resonant scattering of conduction electrons by the $(5 \mathrm{f}, j=5 / 2)$ virtual bound states. This residual resistivity is maximum at the critical composition $x_{\mathrm{c}}=0.43$ and decreases in the ferromagnetic state (see Fig. 9) because the scattering there becomes more and more coherent and because the spin-up and spin-down $5 f$ states become split apart from the Fermi level.

The resistivity minima observed around $400 \mathrm{~K}$ for the non-ferromagnetic samples ([15] and Fig. 9) are explained by a decrease of this resonant scattering with increasing temperature : this is due to the broadening of the Fermi distribution in the narrow $f$ virtual bound state and is enhanced by spin fluctuations [44]. The spin-fluctuation model is now generally considered as being equivalent to a high temperature Kondo model [87]. For a Kondo effect to occur, the $5 f$ state must be a virtual bound state, mixed with the conduction band, the exchange coupling between the localized spin and the conduction electron spin being antiferromagnetic (this is the case for $\left(\mathrm{U}_{x} \mathrm{Th}_{1-x}\right) \mathrm{S}$, see $\S 6)$.

Although crystal-field levels were not observed by neutron scattering, the shallow resistivity maximum observed around $300 \mathrm{~K}$ for $\left(\mathrm{U}_{0.8} \mathrm{Th}_{0.2}\right) \mathrm{S}$ may indicate that the crystal-field structures of the $\mathrm{f}^{n}$ configurations are not completely wiped out by mixing with conduction electrons : the characteristic inverse frequency of a conduction electron is of course much shorter than that of a neutron. This analysis must be considered with caution, because no resistivity maximum is observed at low uranium content [44]. Nevertheless, coexistence of Kondo effect and crystal-field splitting are thought to occur in $\mathrm{CeAl}_{2}$ and to give rise to a complicated resistivity versus temperature behaviour [77].

Finally, one should remark that between $x \simeq 0.20$ and 0.43 the magnetization is inhomogeneous and superparamagnetic effects are observed in the low temperature specific heat; this may mask occurrence of mictomagnetism or spin-glass behaviour [76] in this composition range.

12. Conclusion. - Our study of magnetization, specific heat and neutron scattering, following the electrical resistivity and magnetic susceptibility measurements of Griveau et al. [15], has shown that the critical concentration for appearance of low temperature ferromagnetism in the $\left(\mathrm{U}_{x} \mathrm{Th}_{1-x}\right) \mathrm{S}$ alloys is $x_{\mathrm{c}}=0.43$.

We have tried to understand the electronic structure of these alloys by comparing them to simple models.

We have been able to discard purely localized $5 f^{n}$ configurations, although the $5 \mathrm{f}^{2}$ explains many pro- 
perties of these compounds. A $5 f$ virtual bound state model for dilute uranium alloys, and a narrow 5f-6d hybrid band model for rich uranium alloys were preferred to interconfiguration fluctuation models. Spin fluctuations seem important. Of course, experiments such as the magnetic form factor measurement in US by Wedgwood [5] should be reanalyzed with hybridized $\mathrm{f}$ states, but a correct knowledge of the band structure is then needed.

We are working presently on dilute solutions of $\mathrm{U}, \mathrm{Np}, \mathrm{Pu}$ in ThS, ThSe, ThTe [44] in order to improve our description of actinide impurities in terms of $5 \mathrm{f}$ virtual bound states. High pressure experiments are planned. A detailed study of the behaviour of the $\left(\mathrm{U}_{x} \mathrm{Th}_{1-x}\right) \mathrm{S}$ system around the critical composition for ferromagnetism $x_{c}=0.43$ will be also undertaken.

Acknowledgments. - We wish to thank Dr. Fruchart for allowing us to use his magnetization measurement apparatus at the C.N.R.S., Vitry/s/Seine, and also B. Griveau for allowing us to mention his Hall effect measurements on US and ThS. We are indebted to Professor J. Friedel for many comments and suggestions.

\section{References}

[1] Eastman, E. D., Brewer, L., Bromley, L. A., Gilles, P. W., Lofgren, N. L., J. Am. Chem. Soc. 72 (1950) 4019.

[2] Tetenbaum, M., J. Appl. Phys. 35 (1964) 2468.

[3] Adachi, H., Iмото, S., Technology Report of the Osaka University 23 (1973) 425

[4] Allbutt, M., Junkinson, A. R., Dell, R. M., Nuclear Metallurgy, volume $X$ A.I.M.E. (Waber, Chiotti and Miner, editors, New York) 1964, p. 65.

[5] Wedgwood, F. A., J. Phys. C., Solid State Phys., 5 (1972) 2427.

[6] Grunzweig-Genossar, J., Kuznietz, M., Friedman, F., Phys. Rev. 173 (1968) 562.

[7] Westrum Jr., E. F., Walters, R. R., Flotow, H. E., Osborne, D. W., J. Chem. Phys. 48 (1968) 155

[8] Davis, H. L., Plutonium 1970 and other Actinides, ed. W. N. Miner, vol. 1 (New York : the Metallurgical Society of A.I.M.E.) p. 209.

[9] Eastman, D. E., Kuznietz, M., J. Appl. Phys. 42 (1971) 1396.

[10] ShaleK, P. D., J. Am. Ceram. Soc. 46 (1963) 155.

[11] Cater, E. D., Thorn, R. J., Walters, R. R., Nuclear Metallurgy, volume X, A.I.M.E. (Waber, Chiotti and Miner, editors, New York) 1964, p. 237.

[12] Fisk, Z., Coles, B. R., J. Phys. C., Solid State Phys. 3 (1970) L-104.

[13] Chechernikov, V. I., Shavishvili, T. M., Pletyushin, V. A., Slovyanskikh, V. K., Ellert, G. U., Sov. Phys. J.E.T.P. 27 (1968) 921.

[14] Danan, J., Griveau, B., Marcon, J. P., Gatesoupe, J. P., DE Novion, C. H., Rare Earths and Actinides, Durham Symposium, The Institute of Physics, London-Bristol, 1971, p. 176.

[15] Griveau, B., Marcon, J. P., Gatesoupe, J. P., J. Inorg. Nucl. Chem. 34 (1972) 1535.

[16] Adachi, H., Iмото, S., J. Nucl. Sci. Technol. 6 (1969) 371.

[17] Lehman, G. W., Phys. Rev. 116 (1959) 846.

[18] Davis, H. L., Rare Earths and Actinides, Durham Symposium, The Institute of Physics, London-Bristol, 1971, p. 126.

[19] De Novion, C. H., Costa, P., J. Physique 33 (1972) 257.

[20] Flotow, H. E., Osborne, D. W., Walters, R. R., J. Chem. Phys. 55 (1971) 680

[21] Mott, N. F., Jones, H., The Theory of the Properties of Metals and Alloys (Dover Publications Inc., New York), 1958.

[22] Shenoy, G. K., Kuznietz, M., Dunlap, B. D., Kalvius, G. M., Phys. Lett. A 42 (1972) 61.

[23] Chan, S. K., Lam, D. J., Plutonium 1970 and other Actinides, ed. W. N. Miner, Vol. 1 (New York : The Metallurgical Society of A.I.M.E.) p. 219.

[24] Kuznietz, M., Rare Earths and Actinides, Durham Symposium, The Institute of Physics, London-Bristol, 1971, p. 162.

[25] Allbutt, M., Dell, R. M., J. Inorg. Nucl. Chem. 30 (1968) 705.

[26] Marcon, J. P., Thesis, Orsay (1969), Report CEA-R-3919 (1969).
[27] Damien, D., Inorg. Nucl. Chem. Lett. 7 (1971) 291

[28] De Novion, C. H., Thesis, Orsay (1970). Report CEA-R-4113 (1970).

[29] Marples, J. A. C., J. Phys. \& Chem. Solids 31 (1970) 2431.

[30] Allbutt, M., Dell, R. M., Junkinson, A. R., Marples, J. A., J. Inorg. Nucl. Chem. 32 (1970) 2159.

[31] Furuya, H., Jpn. J. Appl. Phys. 7 (1968) 779.

[32] Kazmierowicz, C. W., Report ANL-6731 (1963).

[33] Wedgwood, F. A., Kuznietz, M., Rare Earths and Actinides, Durham Symposium, The Institute of Physics, LondonBristol, 1971, p. 168.

[34] Gardner, W. E., Smith, T. F., 11 th Inst. Conf. on Low Temp. Phys., St. Andrews (1968), 1377.

[35] Raphael, G., Report CEA-R-3912 (1969).

[36] Suski, W., Trzebiatowski, W., Bull. Acad. Pol. Sci. Ser. Sci. Chim. XII (1964) 277.

[37] Karplus, R., Luttinger, J. M., Phys. Rev. 95 (1954) 1154.

[38] Nakai, E., Ono, F., Takahashi, Y., Mukaibo, T., J. Nucl. Sci. Tech. 7 (1970) 427.

[39] Moser, J. B., Kruger, O. L., J. Appl. Phys. 38 (1967) 3215.

[40] Danan, J., Thesis, Nancy (1972). Report CEA-R-4453 (1973).

[41] Grunzweig-Genossar, J., Solid State Commun. 8 (1970) 1673.

[42] Herpin, A., Théorie du Magnétisme (P.U.F., Paris) 1968.

[43] Wedgwood, F. A., J. Phys. C., Solid State Phys. 7 (1974) 3203.

[44] Haessler, M., De Novion, C. H., Damien, D., Plutonium 1975 and other Actinides (North-Holland Publishing Company, Amsterdam) 1976, p. 649.

[45] ANL Monthly Progress Report ANL-6977 (1964).

[46] Grans, R., Ann. Phys. Leipzig 15 (1932) 28.

[47] Chechernikov, V. I., Pechennikov, A. V., Yarembasn, E. I., Martynova, L. F., Slovyanskikh, V. K., Sov. Phys. JETP 26 (1968) 328.

[48] Williams, D. E. G., The magnetic properties of Matter (Longmans, Green and Co., London) 1966.

[49] Willis, B. T. M., Proc. R. Soc. A 274 (1963) 122.

[50] Hewat, A. H., J. Phys. C., Solid. State Phys. 5 (1972) 1309.

[51] De Gennes, P. G., Lafore, P., Millot, J. P., J. Phys. \& Chem. Solids 11 (1959) 105.

[52] Sato, H., Arrott, A., J. Phys. \& Chem. Solids 10 (1959) 19.

[53] Hutchings, M. T., Solid State Phys. 16 (1964) 227.

[54] Conway, J. G., J. Chem. Phys. 31 (1959) 1002.

[55] De Novion, C. H., C.R. Hebd. Sean. Acad. Sci. B 273 (1971) 26.

[56] Hufner, S., Wertheim, G. K., Cohen, R. L., Wernick, J. H., Phys. Rev. Lett. 28 (1972) 488.

[57] Jaccarino, V., Walker, L. R., Phys. Rev. Lett. 15 (1965) 258.

[58] Brog, K. C., Jones Jr., W. H., Phys. Rev. Lett. 24 (1970) 58 and J. Appl. Phys. 41 (1970) 1003.

[59] Claus, H., Sinha, A. K., Beck, P. A., Phys. Lett. A 26 (1967) 38 and 26 (1967) 611.

[60] Perrier, J. P., Tissier, B., Tournier, R., Phys. Rev. Lett. 24 (1970) 313. 
[61] Garland, J. W., Gonis, A., in Magnetism in Alloys, P. A. Beck and J. T. Waber, editors (A.I.M.E.) 1972, p. 79.

[62] Gupta, K. P., Cheng, C. H., Beck, P. A., Phys. Rev. 133 (1964) A 203.

[63] Chouteau, G., Fourneaux, R., Tournier, R., Lederer, P., Phys. Rev. Lett. 21 (1968) 1082.

[64] Cheng, C. H., WeI, C. T., BeCK, P. A., Phys. Rev. 120 (1960) 426.

[65] Triplett, B. B., Phillips, N. E., Phys. Lett. A 37 (1971) 443.

[66] Doniach, S., EngelSberg, S., Phys. Rev. Lett. 17 (1966) 750.

[67] Fulde, P., Luther, A., Phys. Rev. 170 (1968) 570.

[68] Kouvel, J. S., in Magnetism in Alloys, P. A. Beck and J. T. Waber, editors (A.I.M.E.) 1972, p. 165.

[69] Hahn, A., Wohlfarth, E. P., Helv. Phys. Acta 41 (1968) 857.

[70] Friedel, J., J. Physique Radium 23 (1962) 692.

[71] Marshall, W., Phys. Rev. 118 (1960) 1519.

[72] Berton, A., These, Grenoble (1967).

[73] Edwards, D. M., Proc. R. Soc. A 269 (1962) 338.

[74] De Gennes, P. G., J. Phys. \& Chem. Solids 4 (1958) 223.

[75] Anderson, P. W., Phys. Rev. 124 (1961) 41.

[76] BeCK, P. A., in Magnetism in Alloys, P. A. Beck and J. T. Waber, editors (A.I.M.E.) 1972, p. 211.

[77] Rao, V. U. S., Suski, W., Craig, R. S., Wallace, W. E., 8 th Rare Earth Conference, Remo (Nevada, U.S.A.) 1970 , p. 355
[78] Hirst, L. L., Phis. Kondens. Mater. 11 (1970) 255.

[79] Sales, B. C., Wohlleben, D. K., Phys. Rev. Lett. 35 (1975) 1240.

[80] Campagna, M., Bucher, E., Wertheim, G. K., Buchanan, D. N. E., Longinotti, L. D., Phys. Rev. Lett. 32 (1974) 885.

[81] Triplett, B. B., Dixon, N. S., Boolchand, P., Hanna, S. S., Bucher, E., J. Physique Colloq. 35 (1974) C 6-653.

[82] Brewer, L., J. Opt. Soc. Am. 61 (1971) 1101.

[83] Varma, C. M., Yafet, Y., Phys. Rev. B 13 (1976) 2950.

[84] Hirst, L. L., Conf. on Magnetism and Magnetic Materials, C. D. Graham, J. J. Rhyne, G. H. Lander, Eds., A.I.P. Proc. 'no 24 (New York, 1975) p. 11.

[85] Coqblin, B., Bhattacharjee, A. K., Cornut, B., GonzalezJimeneZ, F., Iglesias-SicARdi, J. R., Jullien, R., Discussion meeting on magnetic semiconductors, Jülich, R.F.A. (september 1975), to be published in the J. of Magnetism and Magnetic Materials.

[86] Andres, K., Graebner, J. E., Ott, H. R., Phys. Rev. Lett. 75 (1975) 1779.

[87] Rivier, N., Zuckermann, M. J., Phys. Rev. Lett. 21 (1968) 904. 